\title{
Optimization and Feasibility of Alizarin Red S Retention on Iron- Loaded Cellulose Nanocomposite Bead
}

\author{
Mitali Sarkar*, Pankaj Sarkar, Swagatam Sarkar, Shanku Denrah \\ Department of Chemistry, University of Kalyani, Kalyani, India \\ Email: msarkar@klyuniv.ac.in, mitaliku@gmail.com
}

Received: 16 September 2020; Revised: 5 December 2020; Accepted: 10 December 2020

\begin{abstract}
Iron(III) loaded cellulose nanocomposite bead, synthesized through sol-gel method, was characterized by Fourier transform infra-red spectroscopy, field emission scanning electron microscopy, energy dispersive spectroscopy, atomic force microscopy, tunneling electron microscopy, and tested for adsorptive removal of alizarin red $\mathrm{S}$ from aqueous solution. The influence of variables such as $\mathrm{pH}$, contact time, initial dye concentration, adsorbent dose and temperature for dye retention were investigated in batch operation. The process was optimized by employing response surface methodology following full factorial and central composite design. The maximum adsorption of $97 \%$ was observed at an optimum condition of $\mathrm{pH} 3.0$, dose of $2.0 \mathrm{gdm}^{-3}$ and shaking time of 45 mins corresponding to the dye concentration of $100 \mathrm{mgdm}^{-3}$ at $303 \mathrm{~K}$. Correlation of cooperative influences of the significant variables and the extent of dye adsorption were represented by a second order polynomial equation. The mutual interactions of the significant variables were presented by $3 \mathrm{D}$ response surface and $2 \mathrm{D}$ contour plots in the design space. The adsorption was better described by Langmuir isotherm and pseudo second order kinetics. The process was spontaneous $\left(-\Delta \mathrm{G}^{\circ}, 48.19 \mathrm{kJmol}^{-1}\right)$, feasible $\left(\Delta \mathrm{S}^{\circ}, 0.284 \mathrm{Jmol}^{-1} \mathrm{~K}^{-1}\right)$ and endothermic $\left(\Delta \mathrm{H}^{\circ}, 71.62 \mathrm{kJmol}^{-1}\right)$. The adsorbent can be regenerated with $\mathrm{NaOH}(10.0$ $\left.\times 10^{-2} \mathrm{M}\right)$ and recycled for reuse, at least for five successive operations.
\end{abstract}

Keywords: Iron-loaded cellulose nanocomposite bead, Alizarin red S adsorption, optimization, isotherm, kinetics, recycling

\section{Introduction}

Dyes, due to long term persistence and huge volume of discharge, belong to the class of one of the critical contaminants. Of the different dyes such as natural and synthetic, the later poses several detrimental effects on water bodies and water habitats. The synthetic dyes found versatile usage in different industries such as leather, textile, paper, rubber, cosmetics, plastics, pharmaceuticals as well as food, due to their bright and lasting colors and resistance to the action of detergent [1]. As a moderate estimation there are about 100,000 commercial dyes, presently in use with an annual production of over $7.0 \times 10^{5}$ tons per year [2]. The resulting discharge of such dyes to the water bodies and streams does not only decrease the per capita availability of fresh water for human use like washing, bathing and drinking, but also pose some threat to human health. The severe consequences are allergic reactions, dermatitis, skin irritation as well as cancer and mutations [3]. The aquatic habitats become threatened as the dyes inhibit the absorption and reflection of sunlight entering water and limiting the biological degradation of water impurities including bacteria.

Alizarin red S, an anthraquinone dye, finds wide applications in textile, leather and paint industries [4]. It is highly

Copyright (C2020 Mitali Sarkar, et al.

DOI: https://doi.org/10.37256/nat.212021644

This is an open-access article distributed under a CC BY license

(Creative Commons Attribution 4.0 International License)

https://creativecommons.org/licenses/by/4.0/ 
toxic and is highly stable towards heat, light and some chemical interactions [5]. It is necessary to remove alizarin red $\mathrm{S}$ from aqueous environment, preferably following a sustainable approach. There are various techniques that include co-precipitation [6], electro-coagulation [7], photo-catalytic degradation [8], electro-Fenton process [9] and adsorption for dye decontamination. Adsorption is one of the most popular removal techniques due to its simple operation, high efficiency, applicability to wide range of concentrations, availability of variety of adsorbents ranging from engineered materials to biomaterials and the recycling ability of the adsorbents. Hynes et al [10] made a comprehensive review on the available techniques as well as different adsorbents for removal of dyes from textile industries. It is still challenging to develop an efficient, cost effective and renewable adsorbent, following simple preparation route, for removal of pollutants including the dyes. Bio-based nanocomposites, particularly, may play a significant role in this regard.

In continuation to our study on Cr(VI) removal on iron(III) loaded nanocomposite bead (FeCNB) [11], the present report describes adsorptive removal of alizarin red S using FeCNB. The synthesized adsorbent and the iron(III) loaded nanocomposite bead (FeCNB) were characterized for its physicochemical and surface character using FTIR (Fourier transform infra-red spectroscopy), FESEM (field emission scanning electron microscopy), EDS (energy dispersive spectroscopy), AFM (atomic force microscopy), and tunneling electron microscopy (TEM) studies. The synthesized material was found to be of nano nature and thermally stable at least up to $200^{\circ} \mathrm{C}$ [11]. The statistical optimization of cooperative interactions of the operational variables such as $\mathrm{pH}$, contact time, initial dye concentration, adsorbent dose and temperature were established following the response surface methodology (RSM) in a two steps process viz. full factorial and central composite design. The former categories the variables in terms of significance, and the optimization of the significant variables were made in the later step. Among the operational variables concentration, time, dose and $\mathrm{pH}$ were found to be significant. A mathematical model correlating the simultaneous as well as cooperative influences of the significant variables and the adsorption extent were developed. Statistical analysis of variance (ANOVA) favored the validity of the derived model. The response surface and contour plots represented the interactive influences of the significant variables.

The ARS-FeCNB interaction best described by Langmuir adsorption isotherm was thermodynamically feasible $\left(\Delta \mathrm{G}^{\circ},-48.19 \mathrm{kJmol}^{-1} ; \Delta \mathrm{H}^{\circ}, 71.62 \mathrm{kJmol}^{-1} ; \Delta \mathrm{S}^{\circ}, 0.284 \mathrm{Jmol}^{-1} \mathrm{~K}^{-1}\right)$, and followed $2^{\text {nd }}$ order kinetics. The nanocomposite bead can be recycled and reused at least for five consecutive adsorption-desorption cycles using $10.0 \times 10^{-2} \mathrm{M} \mathrm{NaOH}$ as the desorption agent.

The present work was undertaken to explore an effective removal strategy of alizarin red S, an anionic dye of the anthraquinone family using bio-nanocomposite. The synthesized nanocomposite adsorbent is unique in respect to its high surface area, porosity, stability, easy mechanical separation and simple route of synthesis from cellulose, the most abundant biopolymer. The process design for optimization in an all variables at a time mode, in contrary to the one variable at a time mode, reflects the true situation of variables interaction, although it requires lesser number of experimental runs. The knowledge gained may be extended to dye wastewater decontamination for real situation and large scale operation. The present renewable bio nanocomposite shows higher capacity compared to the similar reported adsorbents [12-16].

\section{Experimental methods}

\subsection{Chemicals and materials}

All the chemicals and solvents used are of analytical grade. Cellulose powder used was purchased from Loba Chemie, India. ARS was purchased from Merck, India. Stock solution was prepared from known amount of ARS in Milli-Q water. Iron impregnation of cellulose bead was done using $\mathrm{Fe}\left(\mathrm{NO}_{3}\right)_{3} \cdot 9 \mathrm{H}_{2} \mathrm{O}$.

\subsection{Synthesis of iron(III) loaded cellulose nanocomposite bead (FeCNB)}

The adsorbent was synthesized by modification of the nanocellulose bead. Synthesis of CNB was done by liquefaction/dissolution of cellulose, xanthation, alkalization and solidification/coagulation. The formation of the bead occurred via sol-gel transition [17]. The modification of CNB was done by impregnation of $\mathrm{Fe}(\mathrm{III})$ [10\% $\left.\mathrm{Fe}\left(\mathrm{NO}_{3}\right)_{3}\right]$ following shaking for $2 \mathrm{~h}$ at a speed of $100 \mathrm{spm}$ at room temperature. The bead was washed with $\mathrm{D}_{2} \mathrm{O}$ and stored at room temperature under water [11]. 


\subsection{Preparation of ARS solution}

The working solutions were prepared by dilution of the stock ARS solution $\left(1.0 \mathrm{gdm}^{-3}\right)$ with Milli-Q water. The $\mathrm{pH}$ of the solution was adjusted with either $\mathrm{HCl}$ or $\mathrm{NaOH}$ solution of desired concentrations as necessary.

\subsection{Characterization of FeCNB}

Surface analysis of FeCNB was done by scanning electron microscopy (SEM; EVO LS 10 Zeiss instrument, USA), field emission scanning electron microscopy (FESEM; JEOL, JSM-6700F, Japan) and elemental composition by energy dispersive spectroscopy (EDS; FEI QUANTA FEG 250, Japan). Atomic force microscopy (AFM; VEECO, DICP-II, AP-0100, USA) and Transmission electron microscopy (TEM; JEOL, JEM-2100, Japan) were used to determine particle shape and size in nanometer scale along with parcle size distribution. Fourier transform infrared spectroscopy (Perkin Elmer L120-000A, USA) was used to identify the functional groups present in the synthesized bead and changes due to adsorption of ARS on FeCNB (ARS-FeCNB). The thermal stability of the bead was evaluated from thermal study (TGA-DTA; SDT Q 600 V8-2 Build 100, USA) using $\mathrm{Al}_{2} \mathrm{O}_{3}$ as the standard [11]. Estimation of ARS concentration in solution before and after adsorption was made by UV-Vis spectral study (VIS-7200A Perkin-Elmer, USA) at $423 \mathrm{~nm}$.

\subsection{Batch experiment}

Batch adsorption experiment was performed using ARS solution of different known concentrations at a constant shaking rate with a fixed adsorbent dose under controlled temperature utill equilibrium was reached. The $\mathrm{pH}$ of the solution was maintained either by dilute $\mathrm{HCl}$ and $\mathrm{NaOH}$ solution. The influence of operational variables $\mathrm{pH}$, contact time, initial dye concentration, temperature, adsorbent dose and shaking speed on the adsorption efficiency were examined.

Adsorption potential $\left(\mathrm{q}_{\mathrm{t}}\right)$, expressed as extent retention (Eq 1) and adsorption efficiency $(\phi)$, expressed as percent retention (Eq 2), were calculated as,

$$
\begin{gathered}
q_{t}=\frac{C_{0}-C_{e}}{m} \times V \\
\phi=\frac{C_{0}-C_{e}}{C_{0}} \times 100
\end{gathered}
$$

where, $C_{0}$ and $C_{e}$ were the initial and equilibrium ARS concentration in solution $\left(\mathrm{mgdm}^{-3}\right)$ respectively, $\mathrm{m}$ is the mass $(\mathrm{g})$ of FeCNB and $V\left(\mathrm{~cm}^{-3}\right)$ was the volume of the dye solution.

Desorption of ARS was carried out using suitable eluent of definite strength. A fixed amount of dye loaded FeCNB was shaken with the eluent at a constant shaking rate of $100 \mathrm{spm}$ under controlled temperature utill equilibrium was established. $\mathrm{NaOH}$ solution of varying concentrations was used to desorb ARS and regenerate FeCNB. The adsorptiondesorption process was repeated to determine the recycling efficiency of FeCNB.

\subsection{Statistical design and process optimization}

In conventional method employing 'one variable at a time' approach, the mutual and interactive effects of the variables cannot be considered. Moreover this requires large number of experiments to determine optimum levels and it is time consuming.

The statistical experimental design such as response surface methodology (RSM) employing full factorial design (FFD) and central composite design (CCD) may overcome such limitations [18]. The beauty of RSM is that it estimates main effects as well as interaction effects and optimizes all the operating variables collectively, known as "all variable at a time" approach. The statistical analysis of variance (ANOVA) was performed to test the suitability of the design model. In the first step the significant variables, among the set of experimental variables, were evaluated from the Pareto chart, using FFD [19]. The significant variables were subsequently optimized in CCD. A polynomial equation, in coded 
term Eq. (3), was built to correlate the response with the interactive effects of the variables, at the optimized condition [20].

$$
Y=\beta_{0}+\sum_{i=1}^{k} \beta_{i} x_{i}+\sum_{i=1}^{k} \sum_{j=1}^{k} \beta_{i j} x_{i} x_{j}+\sum_{i=1}^{k} \beta_{i i} x_{i}^{2}+\varepsilon
$$

where, $Y$ indicates the response (adsorption capacity), $\beta_{0}$ is the constant term, $\beta_{i}, \beta_{i i}$ and $\beta_{i j}$ represent coefficient for linear, quadratic and interaction effect respectively. $X_{i}$ and $X_{j}$ represent the independent variable and $€$ is the random error.

\section{Results and discussion}

\subsection{Characterization of $\mathrm{FeCNB}$}

A comparison of FTIR for FeCNB and that after ARS adsorption (ARS-FeCNB) was carried out to investigate the changes in vibration frequency of the functional groups of FeCNB due to the dye adsorption (Figure 1). The broad band at $3414 \mathrm{~cm}^{-1}$ for FeCNB and $3401 \mathrm{~cm}^{-1}$ for ARS-FeCNB were attributed to -OH stretching frequency while bands at $2901 \mathrm{~cm}^{-1}$ for FeCNB and $2897 \mathrm{~cm}^{-1}$ for ARS-FeCNB were attributed to -C-H group stretching vibrations. The band arising at $2127 \mathrm{~cm}^{-1}$ for FeCNB and that at $2132 \mathrm{~cm}^{-1}$ for ARS-FeCNB was due to $-\mathrm{C}=\mathrm{C}$ symmetry. Similarly band attributed to $-\mathrm{OH}$ bending frequency was found at $1651 \mathrm{~cm}^{-1}$ for FeCNB and at $1648 \mathrm{~cm}^{-1}$ for ARS-FeCNB. A new band due to $\mathrm{H}-\mathrm{C}-\mathrm{H}$ and $\mathrm{O}-\mathrm{C}-\mathrm{H}$ bending (in plane) at $1424 \mathrm{~cm}^{-1}$ was appeared after ARS adsorption that may be due to the deformation of cyclic ring. Bands corresponding to $\mathrm{C}-\mathrm{H}$ bending (in plane) $\left(1374 \mathrm{~cm}^{-1}\right), \mathrm{C}-\mathrm{O}-\mathrm{H}$ bending at $\mathrm{C}-6$ (1163 $\left.\mathrm{cm}^{-1}\right), \mathrm{C}-\mathrm{C}, \mathrm{C}-\mathrm{OH}, \mathrm{C}-\mathrm{H}$ ring and side group $\left(1062 \mathrm{~cm}^{-1}\right), \mathrm{C}-\mathrm{O}-\mathrm{C}, \mathrm{C}-\mathrm{C}-\mathrm{O}, \mathrm{C}-\mathrm{C}-\mathrm{H}$ deformation and stretching frequency (894-898 $\left.\mathrm{cm}^{-1}\right)$, C-H deformation (620-605 $\left.\mathrm{cm}^{-1}\right)$ [21] were observed both in FeCNB and ARS-FeCNB. The band corresponding to $\mathrm{O}-\mathrm{H}$ bending (out of plane) at $769 \mathrm{~cm}^{-1}$ in $\mathrm{FeCNB}$ disappeared after ARS adsorption. Peaks at 1236 , $1160,1068 \mathrm{~cm}^{-1}$ were ascribed to $\mathrm{SO}_{3}{ }^{2-}$ salt (based on the $\mathrm{RSO}_{3} \mathrm{Na}$ form of the dye) [22]. Peaks at 508 and $575 \mathrm{~cm}^{-1} \mathrm{due}$ to Fe-O bond stretching frequency [23] in FeCNB were slightly shifted to 509 and $581 \mathrm{~cm}^{-1}$ after ARS adsorption. The observed changes in some characteristic peaks in ARS-FeCNB may be indicated as a result of interaction between ARS and FeCNB.

The surface morphology of FeCNB and ARS-FeCNB was investigated from FESEM images at different magnifications along with EDS analysis. The adsorbent beads were found to be of nano nature and spherical in shape having approximate size of $10 \mathrm{~nm}$. EDS study showed characteristic peaks corresponding to the presence of $\mathrm{C}$, $\mathrm{O}$ and $\mathrm{Fe}$ (Figure 2). The peaks due to $\mathrm{C}$ and $\mathrm{O}$ were found below $0.5 \mathrm{keV}$ and $\mathrm{Fe}$ at $0.5,6.5$ and $7.0 \mathrm{keV}$ (a). In addition peaks at 2.0 and $2.5 \mathrm{keV}$ corresponding to element $\mathrm{Na}$ and $\mathrm{S}$ respectively [24] were observed in ARS-FeCNB (b). Elemental composition of FeCNB and ARS-FeCNB presented in Table 1 indicated the retention of ARS on FeCNB.

Table 1. Elemental composition of FeCNB and ARS-FeCNB from EDS

\begin{tabular}{ccc}
\hline \multirow{2}{*}{ Element } & \multicolumn{2}{c}{ Weight \% } \\
\cline { 2 - 3 } & FeCNB & ARS-FeCNB \\
\hline $\mathrm{C}(\mathrm{K})$ & 23.46 & 53.11 \\
$\mathrm{O}(\mathrm{K})$ & 65.61 & 32.24 \\
$\mathrm{Fe}(\mathrm{K})$ & 10.93 & 14.19 \\
$\mathrm{~S}(\mathrm{~K})$ & & 0.27 \\
$\mathrm{Na}(\mathrm{K})$ & & 0.19 \\
Total & 100.00 & 100.00 \\
\hline
\end{tabular}




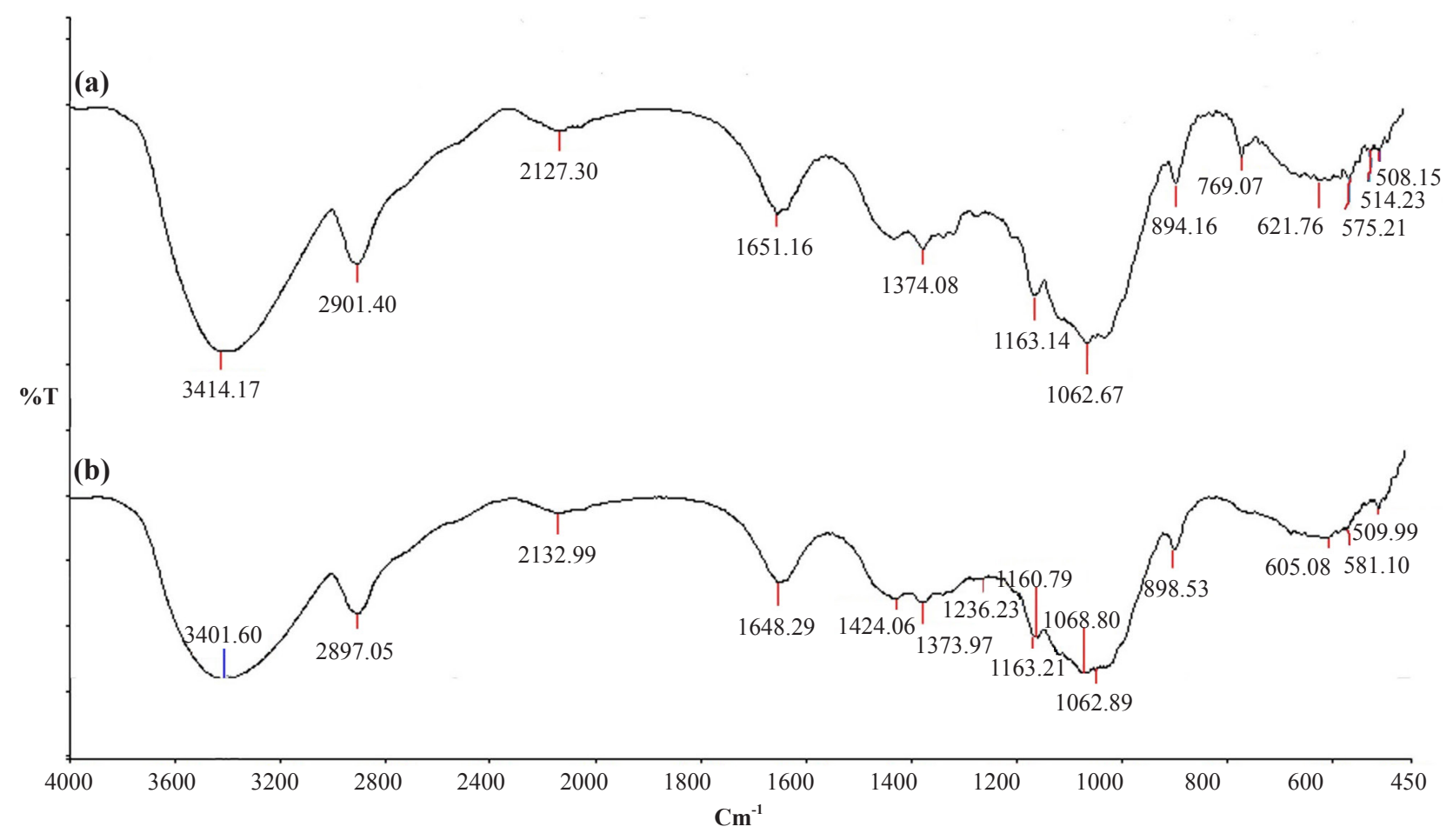

Figure 1. FTIR spectral pattern of (a) FeCNB (b) ARS-FeCNB
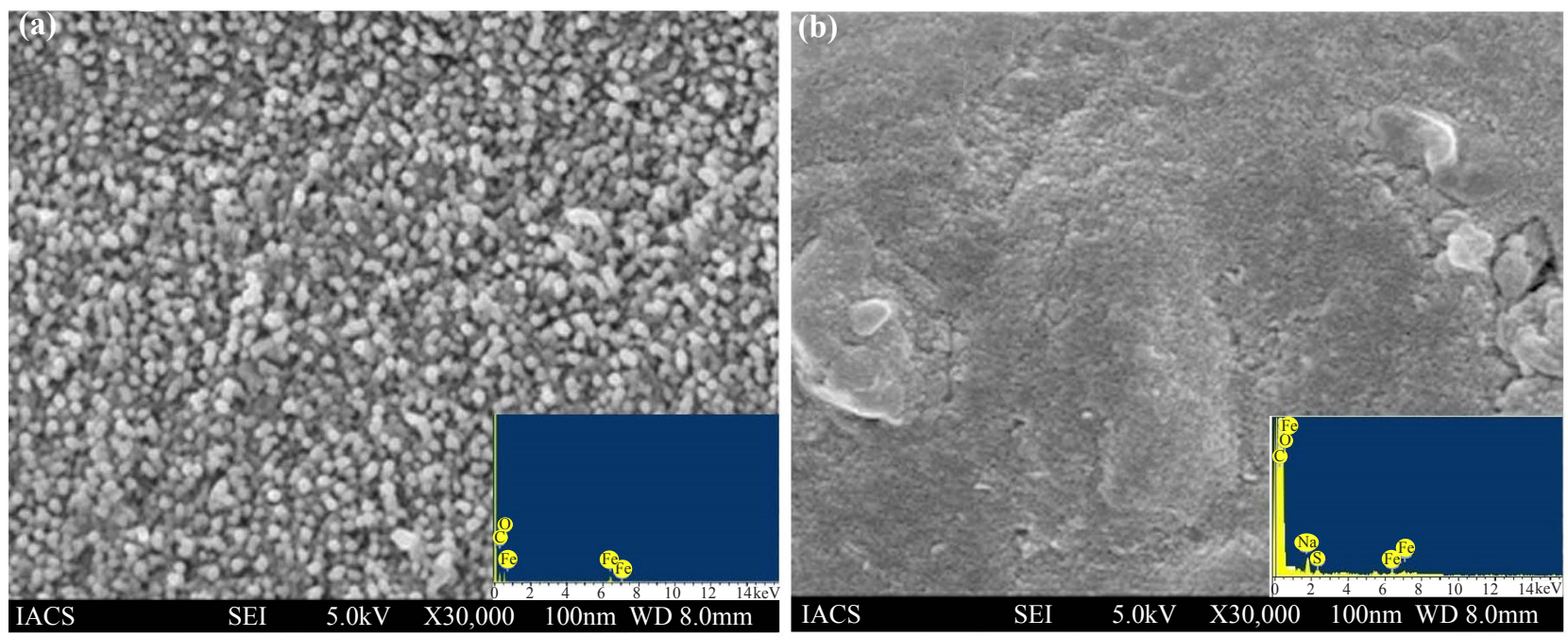

Figure 2. FESEM image with EDS inset (a) FeCNB (b) ARS-FeCNB

\subsection{Influence of single variables}

In an aim to find the influence of single variable on the retention of ARS on FeCNB each one was varied keeping all others fixed and the range of the variables for attainment of equilibrium was determined. Adsorption of ARS was influenced by the different operational variables such as $\mathrm{pH}$, contact time, initial dye concentration, adsorbent dose and temperature. The variables were optimized to maximize the ARS retention on FeCNB. 


\subsubsection{Effect of $p H$}

The retention pattern of ARS on FeCNB may be explained by the surface charge of FeCNB and pH dependent behavior of ARS. The present study was conducted in the $\mathrm{pH}$ range from 2 to 10 . The higher retention (\%) was observed in $\mathrm{pH}$ region 3 to 6.8 . With further increase of $\mathrm{pH}$ retention percent decreased gradually up to $\mathrm{pH} 7.3$ and sharply beyond $\mathrm{pH} 8.0$ (Figure 3a). At lower solution $\mathrm{pH}\left(<\mathrm{pH}_{\mathrm{ZPC}}\right)$ the protonation of the functional groups on $\mathrm{FeCNB}\left(\mathrm{pH}_{\mathrm{ZPC}}\right.$ : 7.58) was more favored. The FeCNB surface becomes positively charged and develops affinity for retention of anionic species [25]. Thus, retention of the anionic dye ARS on the positively charged FeCNB at lower $\mathrm{pH}\left(<\mathrm{pH}_{\mathrm{ZPC}}\right)$ occurred via electrostatic attraction. It was found that maximum retention (97\%) of ARS $\left(100 \mathrm{mgdm}^{-3}\right)$ on FeCNB occurred at $\mathrm{pH}$ 3.0 which decreased to $80 \%$ at $\mathrm{pH} 6.8$ and further decreased to $25 \%$ at $\mathrm{pH} 10.0$. The decrease in the retention at higher $\mathrm{pH}$ was due to the repulsive behavior between the dye and the negatively charge surface of FeCNB.

\subsubsection{Effect of contact time}

The present study was carried out with three different ARS concentrations viz. 50, 100, $150 \mathrm{mgdm}^{-3}$ with variation of time utill the attainment of the equilibrium. Percent retention of ARS was rapid at the initial stage, may be due to the availability of large vacant adsorbent sites as well as a high concentration gradient between the solution and the adsorbent phase [26]. Progressively as the active sites are used up the dye retention became retarded and eventually reached equilibrium. It was found that the adsorption equilibrium, as characterized by the appearance of a flat plateau was attained at 45 minutes (Figure $3 b$ ).

\subsubsection{Effect of initial dye concentration and temperature}

The effect of initial dye concentrations on retention was investigated using solution concentration of $50,100,150$ $\mathrm{mgdm}^{-3}$ corresponding to a fixed adsorbent dose at three different temperatures viz. 290, 300 and $310 \mathrm{~K}$. It was found that with the dye concentration increased, the extent of retention was increased for all the studied temperatures (Figure $3 c$ ). This was due to the availability of more surface active sites of Fence. With the increase of initial dye concentration the mass gradient between the solution and the adsorbent surface increased resulting an increase of the driving force for the transfer of dye molecules from bulk solution to the adsorbent surface.

At higher dye concentration the lower percent of retention was due to the lack of available active sites. As the available active surface was increasingly occupied the binding capacity of the adsorbent decreased and on approaching equilibrium the adsorption extent reached an almost constant value [27]. The retention profile of ARS followed a similar nature for all the studied temperatures. The extent of retention was increased with a rise in temperature for all the studied dye concentrations.

\subsubsection{Effect of FeCNB dose}

The effect of FeCNB dose on ARS retention was studied in the range 1-5 $\mathrm{gdm}^{-3}$. It was found that at $\mathrm{pH} 3.0$ and shaking time of 45 minutes the maximum retention was achieved at $2.0 \mathrm{gdm}^{-3}$. The percent retention was increased initially with increase in dose, attained a maximum at equilibrium and remained constant thereafter (Figure $3 \mathrm{~d}$ ). This may be attributed by the fact that with increase of adsorbent dose the surface active sites increased and adsorption facilitated. Due to the possible aggregation of active sites with increase of dose beyond equilibrium the extent of retention remained unaltered [28]. 
(a)

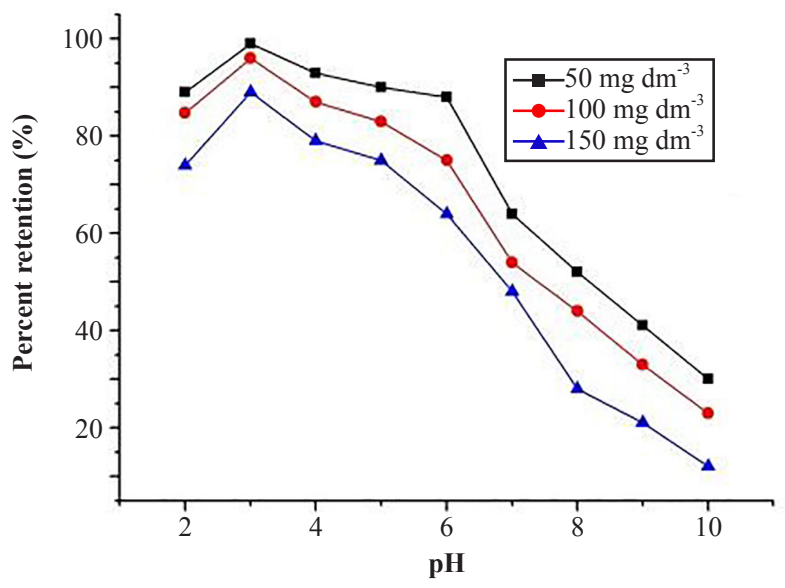

(c)

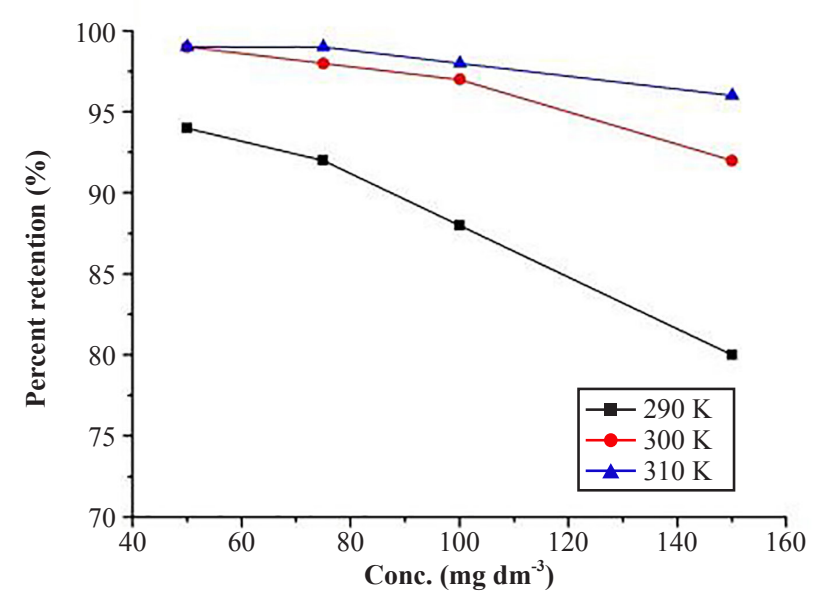

(b)

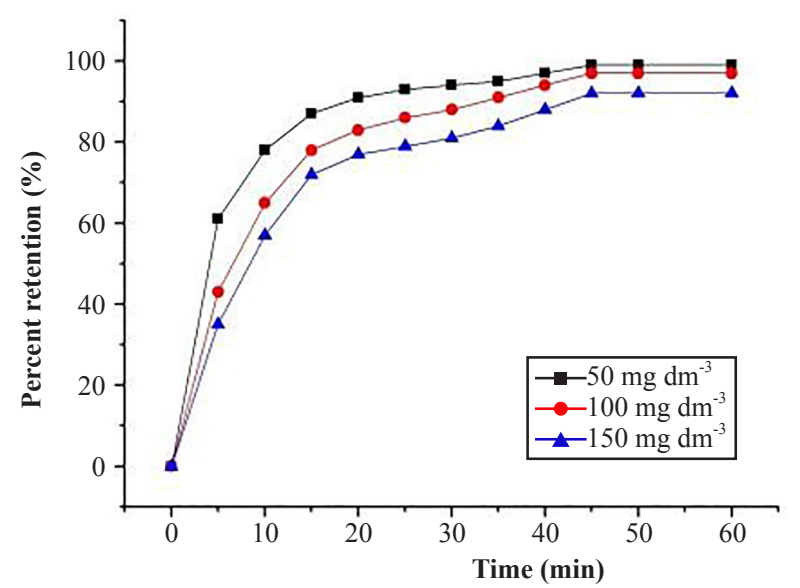

(d)

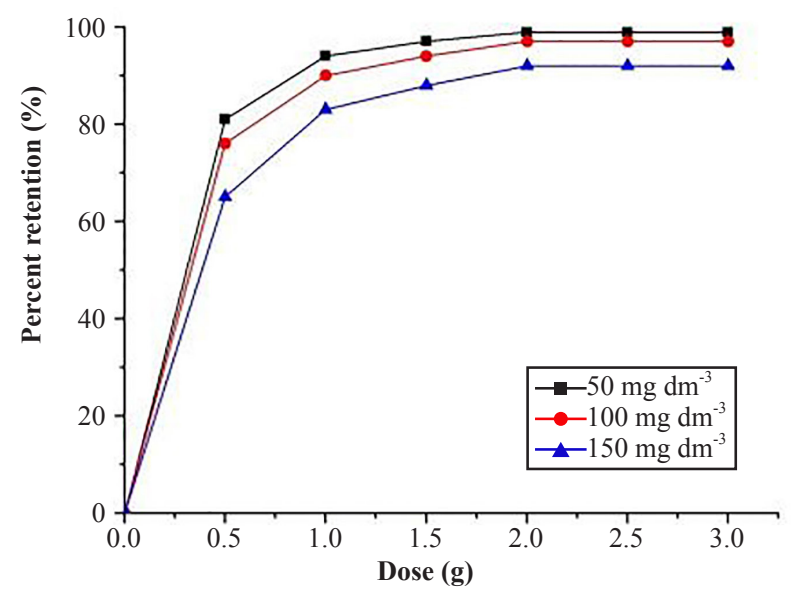

Figure 3. Effect of operational parameters for ARS retention on FeCNB (a) $\mathrm{pH}$ (b) contact time (c) initial concentration (d) dose

\subsection{Process optimization using RSM}

\subsubsection{Scrutiny of variables from Pareto chart and building of FFD}

The operational variables such as $\mathrm{pH}, \mathrm{FeCNB}$ dose, contact time, ARS concentration and temperature were found to have some influence on the adsorption in the univariate operation variables. The mutual influence of such variables can be modeled through RSM. The category of variables (significant and not significant) may be ascertained from the Pareto chart following a full factorial $\left(2^{5}\right)$ design employing Design-Expert 8.0 software. It considers that the interaction effects among the three or more variables are small compared to two variables interaction effects and the main effects and [29]. The FFD assumes that the sparsity-of-effects principle is valid and is build considering all possible combinations of variables across all the levels $[($ higher, +1$)$ and (lower, -1$)]$.

In the present case cooperative influence of $\mathrm{pH}$, dose, contact time, concentration and temperature on the adsorption efficiency (response) was evaluated. A full factorial $\left(2^{5}\right)$ design using Design-Expert 8.0 software was employed. It was assumed that interaction effects among the three or more variables were small compared to the main effects and two variables interaction effects [29]. The category of variables (significant and not significant), through the main effects, was scrutinized at $95 \%$ confidence interval $(p=0.05)$ from the Pareto chart (Figure $4 a)$. The height corresponding to each bar in the Pareto chart is a measure of the extent and the sign indicates the nature of influence (positive or negative) of the variable/s on the response. The bars above the upper threshold t-limit (Bonferroni) correspond to significant variables while those below the lower threshold of the t-limit correspond to non-significant variables. The 
bars in between Bonferroni limit and the lower t-limit may possibly be significant. The influence of single variables is represented by hollow bars while the solid bars represent the multiple or combined influences of the variables. In order to identify the significant variables and to estimate the effect of each single variable on response only the hollow bars were considered in the present case.

It was estimated that the percentage contribution of each variable to the response (PCR) follow an order as, concentration (D: $34.53 \%)>$ dose (B: $26.60 \%)>$ time $(\mathrm{C}: 18.81 \%)>\mathrm{pH}(\mathrm{A}: 11.30 \%)>$ temperature $(\mathrm{E}: 1.11 \%)$. Thus, concentration had the most prominent influence on the response while the temperature the least. The length of the bar indicated that concentration (D), dose (B), time (C) and $\mathrm{pH}(\mathrm{A})$ were the significant variables. All the significant variables other than the concentration of dye showed positive influence on the response, so the study was conducted at each predetermined fixed concentration. In the next step of $\mathrm{CCD}$, the significant variables viz., $\mathrm{pH}$, dose and time were optimized to achieve the maximum efficiency.

\subsubsection{Optimization of variables by $C C D$}

At the step of optimization a second order central composite design (CCD) matrix was built up with the three significant variables $(\mathrm{k})$ in the present case. All the variables were coded at five levels [very low $(-\alpha),-1$ (low), 0 (central), +1 (high) and very high $(+\alpha)$ ] (Table 2). The design was built considering center, axial and factorial points of the significant variables. The required number of experimental data points (REDP) to construct the design was evaluated from the equation (4),

$$
\mathrm{REDP}=2^{\mathrm{k}}(\text { factorial })+2 \mathrm{k}(\text { axial })+6(\text { center })
$$

In the present case the REDP was found to be 20 .

Table 2. Matrix layout of CCD

\begin{tabular}{|c|c|c|c|c|}
\hline \multirow{2}{*}{ Run no. } & \multicolumn{3}{|c|}{ Coded variable } & \multirow{2}{*}{ Adsorption efficiency (\%) } \\
\hline & $\mathrm{A}$ & $\mathrm{B}$ & $\mathrm{C}$ & \\
\hline 1 & -1 & -1 & 1 & 48 \\
\hline 2 & -1 & 1 & -1 & 62 \\
\hline 3 & 0 & 0 & 0 & 94 \\
\hline 4 & 1 & -1 & -1 & 45 \\
\hline 5 & 0 & 0 & 0 & 93 \\
\hline 6 & -1 & 1 & 1 & 58 \\
\hline 7 & 1 & 1 & -1 & 75 \\
\hline 8 & -1 & -1 & -1 & 45 \\
\hline 9 & 1 & -1 & 1 & 58 \\
\hline 10 & 0 & 0 & 0 & 93 \\
\hline 11 & 0 & 0 & 0 & 96 \\
\hline 12 & 1 & 1 & 1 & 83 \\
\hline 13 & 0 & 0 & 0 & 93 \\
\hline 14 & 0 & 0 & 0 & 95 \\
\hline 15 & 0 & 1.68 & 0 & 84 \\
\hline 16 & 1.68 & 0 & 0 & 55 \\
\hline 17 & -1.68 & 0 & 0 & 51 \\
\hline 18 & 0 & 0 & 1.68 & 81 \\
\hline 19 & 0 & 0 & -1.68 & 78 \\
\hline 20 & 0 & -1.68 & 0 & 40 \\
\hline
\end{tabular}


A second order polynomial (Eq. 5) correlating significant variables and the response (Y) was built as,

$$
\mathrm{Y}=93.6463+6.0584 \mathrm{~A}+11.0340 \mathrm{~B}+3.2454 \mathrm{C}+3.5 \mathrm{AB}+2.75 \mathrm{AC}-1.5 \mathrm{BC}-17.2351 \mathrm{~A}^{2}-10.5661 \mathrm{~B}^{2}-6.8301 \mathrm{C}^{2}
$$

The sensitivity analysis, to ascertain the significance of the model, was tested from analysis of variance (ANOVA) and Fisher's F-parameter [30] (Table 3). The F-value compares between the mean square of the model and the residuals. The p-value is defined as the smallest level of significance leading to rejection of the null hypothesis. Thus, when p-values are less than 0.05 the effects of variables in response become statistically significant. The model F-value indicated that the derived model was significant ( $\mathrm{p}$-value $<0.0001$ ). Student's t-test was carried out to determine whether the calculated main and interaction effects were significantly different from zero. In the present model A, B, C, AB, AC, A ${ }^{2}$, $\mathrm{B}^{2}$ and $\mathrm{C}^{2}$ were found to be significant. Quality of the model developed was determined from $\mathrm{R}^{2}$ (regression coefficient) parameter. The value of $\mathrm{R}^{2}$ close to 1.000 favored the model. In the present case a value of $\mathrm{R}^{2}$ equal to 0.9950 approved the model validity with $99.50 \%$ accuracy. The adequate precision measures the signal to noise ratio and values greater than 4 was considered as appropriate for the desired model [31]. In the present model, the adequate precision was found to be 34.64. This suggested that the model, predicting adsorption, was appropriate to navigate the design space.

Table 3. ANOVA of CCD

\begin{tabular}{|c|c|c|c|c|c|c|}
\hline Parameter $r$ & S.S & $\mathrm{df}$ & M.S & F-value & $\mathrm{p}$-value Prob $>\mathrm{F}$ & Influence \\
\hline Model & 7529.367 & 9 & 836.5964 & 202.5414 & $<0.0001$ & Significant \\
\hline A-pH & 458.1626 & 1 & 458.1626 & 110.9219 & $<0.0001$ & Significant \\
\hline B-Dose & 1688.767 & 1 & 1688.767 & 408.8534 & $<0.0001$ & Significant \\
\hline C-Time & 117.137 & 1 & 117.137 & 28.35905 & 0.0005 & Significant \\
\hline $\mathrm{AB}$ & 98.231 & 1 & 98.231 & 23.72596 & 0.0009 & Significant \\
\hline $\mathrm{AC}$ & 60.522 & 1 & 60.522 & 14.6471 & 0.004 & Significant \\
\hline $\mathrm{BC}$ & 18.142 & 1 & 18.142 & 4.35783 & 0.0664 & Not significant \\
\hline $\mathrm{A}^{\wedge} 2$ & 3360.182 & 1 & 3360.18 & 813.5058 & $<0.0001$ & Significant \\
\hline $\mathrm{B}^{\wedge} 2$ & 1741.746 & 1 & 1741.746 & 421.6797 & $<0.0001$ & Significant \\
\hline $\mathrm{C}^{\wedge} 2$ & 437.9935 & 1 & 437.9935 & 106.039 & $<0.0001$ & Significant \\
\hline Residual & 37.17446 & 9 & 4.130496 & & & \\
\hline Lack of fit & 29.17446 & 5 & 55.834893 & 2.917446 & 0.1608 & Not significant \\
\hline
\end{tabular}

$\mathrm{R}^{2}=0.9950$, Adjusted $\mathrm{R}^{2}=0.9901$, Adequate precision $=34.64, \mathrm{~S} . \mathrm{S}$ : sum square, df: degree of freedom, M.S: mean square

The correlation between the experimental and predicted (model) response was made in Figure $4 \mathrm{~b}$. It was seen that almost all the data points were close to the straight line, indicating that the developed model was appropriate and adequate. 
(a)

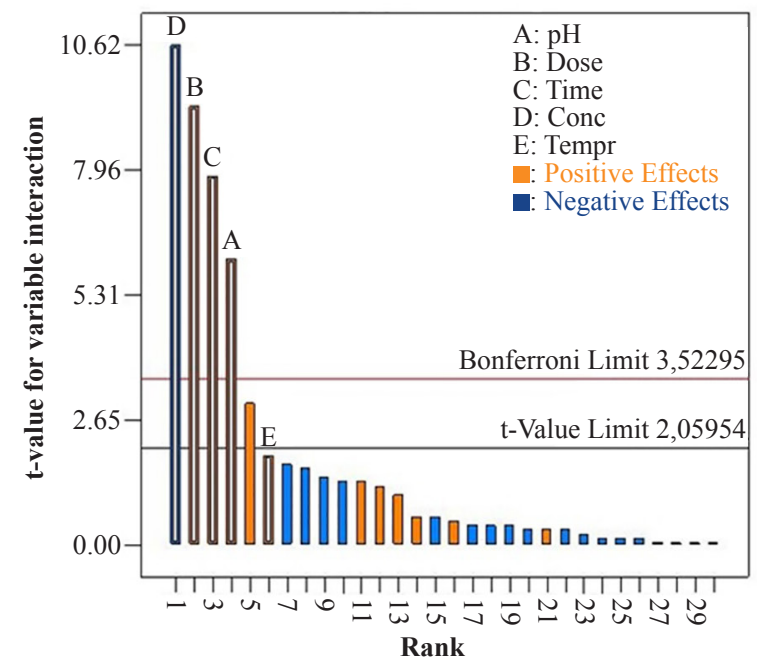

(b)

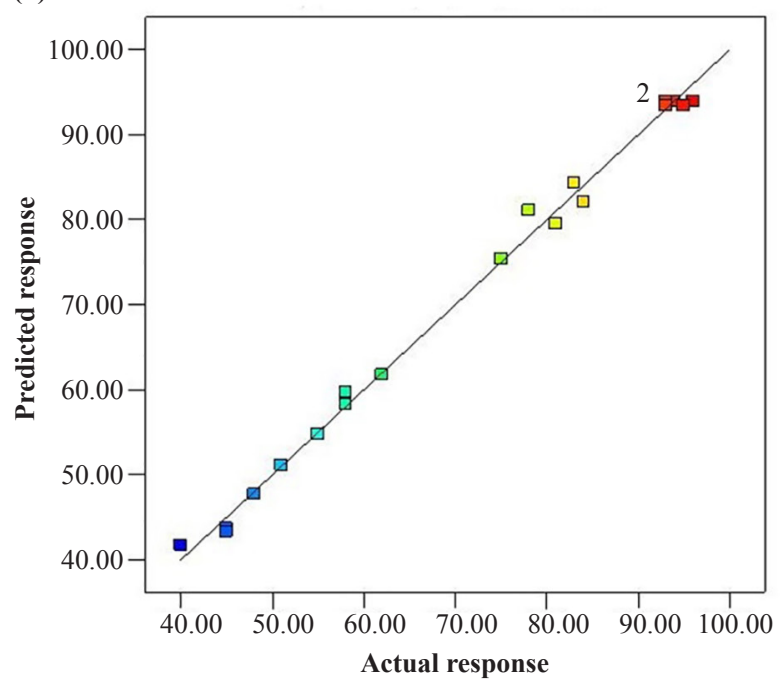

Figure 4. (a) Pareto chart (b) Correlation of actual and predicted response

\subsubsection{Mutual interactions of significant variables}

The mutual interaction effects between each pair of significant variables and their optimum values were elucidated through 3D surface and contour plots. Figures 4(a) and 4(b) represented 3D surface and contour plots respectively for the interaction between $\mathrm{pH}$ and dose (time fixed). Adsorption efficiency was found to increase as the $\mathrm{pH}$ and adsorbent dosage increased. The adsorption was found effective in the $\mathrm{pH}$ range of 3 to 6 and with increased dosage up to 2.0 $\mathrm{gdm}^{-3}$, after which it did not change appreciably. In this $\mathrm{pH}$ range the adsorbent surface $\left(\mathrm{pH}_{\mathrm{ZPC}}: 7.28\right)$ being positively charged attracts the anionic ARS dye. With increased adsorbent dosage the enhanced number of available sites resulted in increased dye adsorption. Beyond optimized adsorbent dose the saturation of adsorbent active sites with dye molecules may possibly occurred and no further increase in adsorption was observed with further increase of adsorbent dosage. Similar observation was reported [32] for adsorption of metals on Lemongrass. Self-binding of adsorbent may reduce the binding sites of adsorbent at higher dose. Figures 4(c) and 4(d) representing the 3D surface and contour plots respectively, showed dependency of adsorption efficiency on $\mathrm{pH}$ and time (dose fixed). Adsorption efficiency increased as both the $\mathrm{pH}$ and adsorption time increased up to a point and then decreased. The highest percent adsorption was recorded at $\mathrm{pH}$ range 4-6 and contact time of 45 mins. The dye-adsorbent interaction in this $\mathrm{pH}$ region was demonstrated as electrostatic between the anionic dye and the positively charged surface site of the adsorbent. Initially, the dye removal was faster than during the later stage and after the optimum time saturation in adsorption was observed. The fast adsorption of the dye at the initial time was due to the availability of plenty active sites on the surface of the adsorbent. With gradual occupancy of the active sites the adsorption slowed down and reached a maximum value at the equilibrium of 45 mins. All the vacant sites on the adsorbent surface being occupied, further increase in contact time did not show any increase in adsorption. The lower adsorption rate at later stage may be due to the gradual occupancy of dye molecules on binding sites [33]. The mutual interaction between dose and time ( $\mathrm{pH}$ fixed) was illustrated by the 3D surface plot in Figure 5(e) and contour plot in Figure 5(f). Adsorption efficiency increased appreciably with adsorption time and gradually with adsorbent dosage. Initial increase of dose with progress of time leads to increase of adsorption due to availability of more adsorbent surface and prolonged dye-adsorbent interaction. Subsequently, the equilibrium was reached as a result of saturation of adsorbent active sites with dye molecules. 
(a)

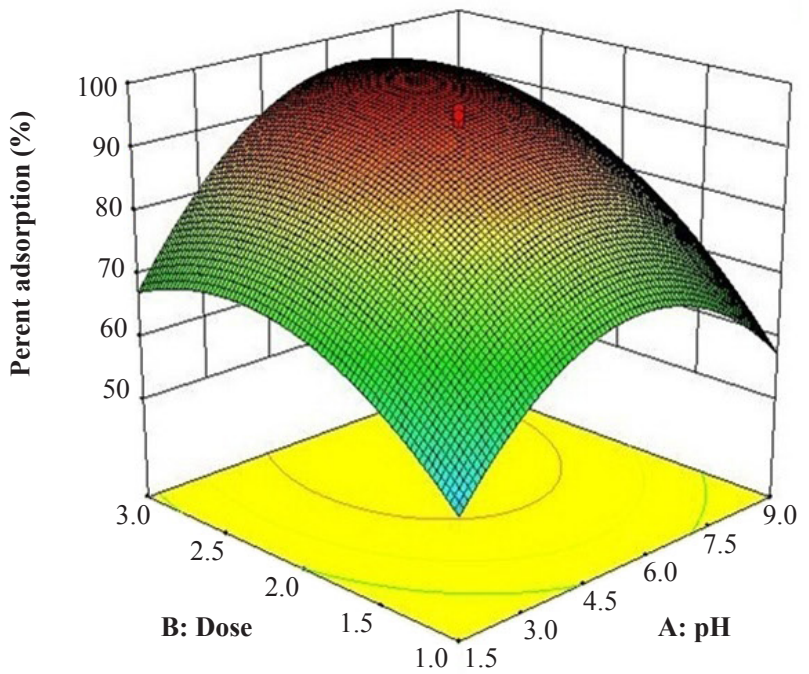

(c)

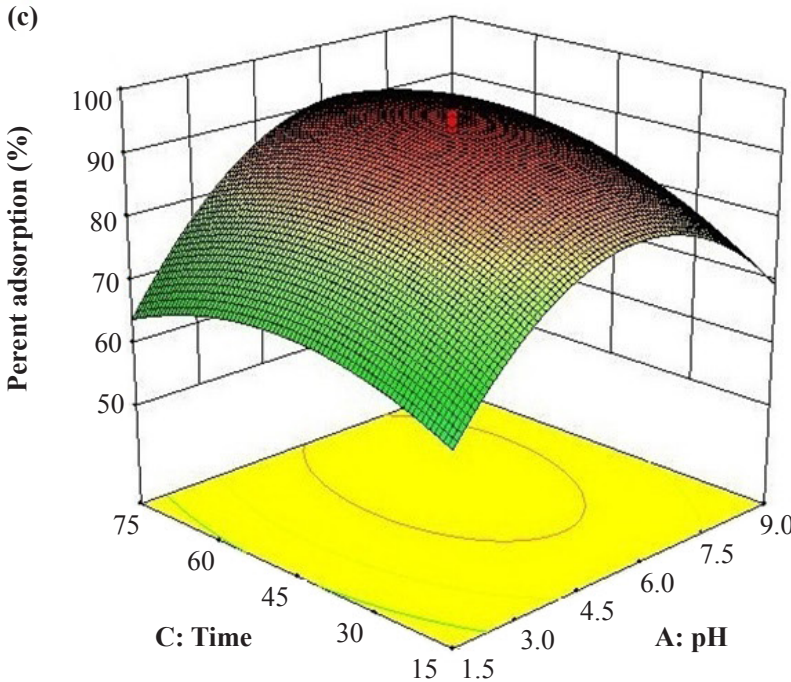

(e)

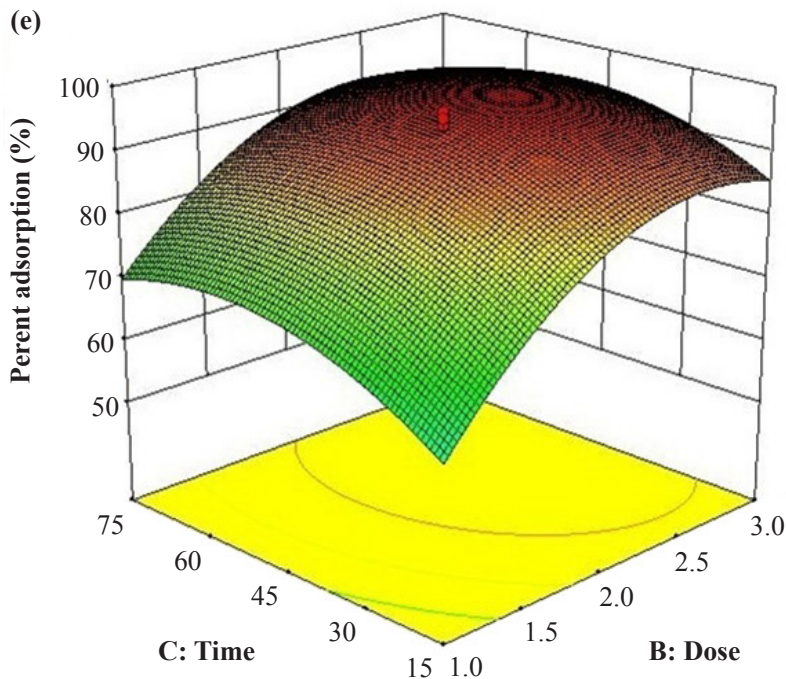

(b)

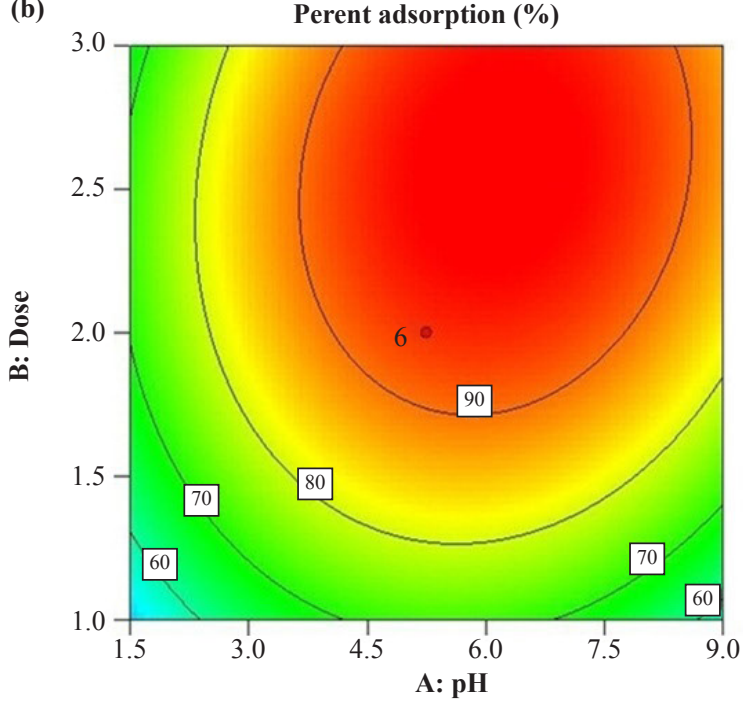

(d)
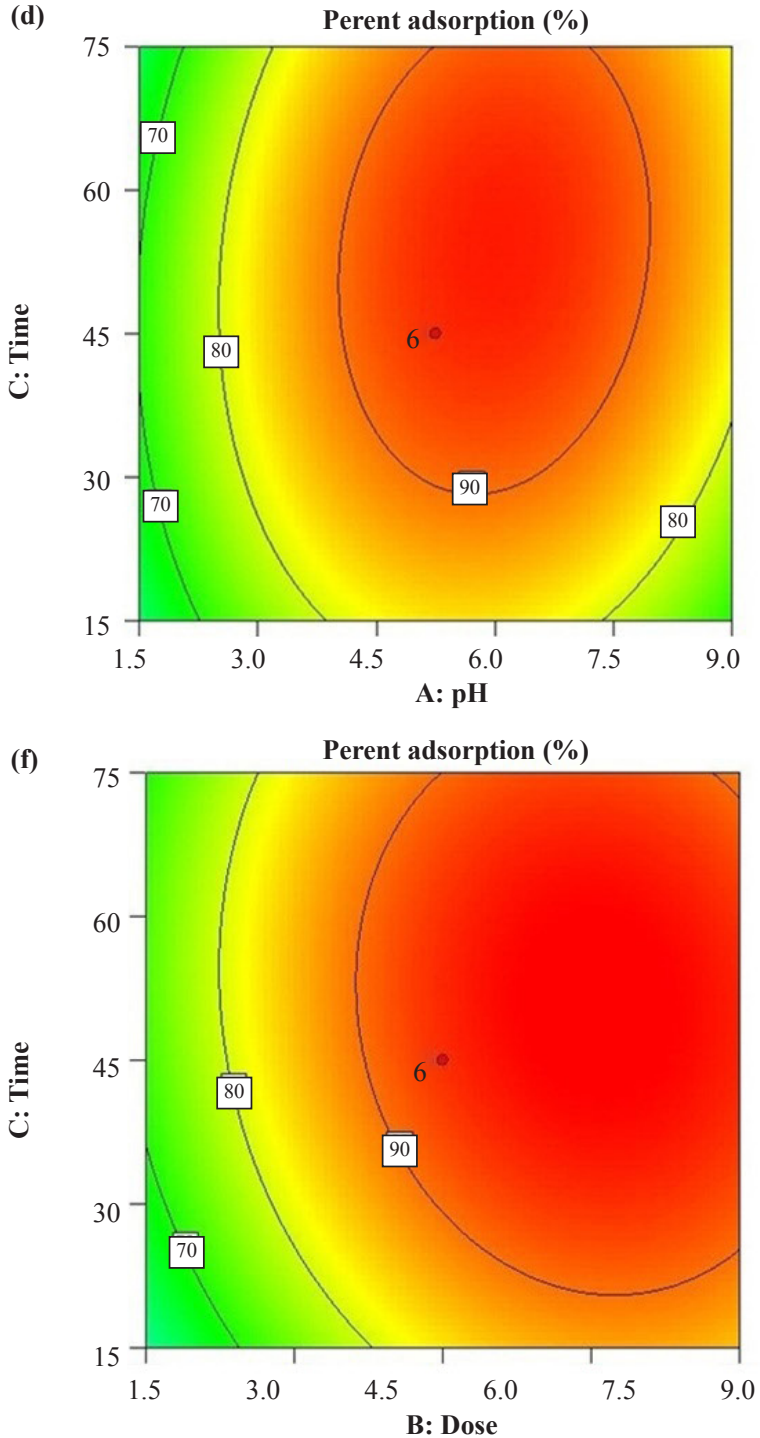

Figure 5. (a), (c), (e) 3D Response surface mapping, (b), (d), (f) 2D Contour plot 


\subsection{Adsorption isotherm}

The equilibrium relationship between the adsorbate and adsorbent surface was presented by isotherm models. Among the different models Langmuir, Freundlich, Tempkin and Dubinin-Radushkevich isotherm were studied.

\subsubsection{Langmuir isotherm}

Langmuir isotherm model illustrates the uptake of solute occurs on a homogeneous surface by monolayer formation and without any interaction of adsorbed molecules. The linear form of the Langmuir isotherm [34] was expressed as,

$$
\frac{C_{e}}{q_{e}}=\frac{1}{Q_{\max } b}+\frac{C_{e}}{Q_{\max }}
$$

where, $Q_{\max }\left(\mathrm{mgg}^{-1}\right)$ and $b\left(\mathrm{dm}^{3} \mathrm{mg}^{-1}\right)$ were the Langmuir isotherm constants representing the adsorption capacity and the energy of adsorption respectively. $C_{e}\left(\mathrm{mgdm}^{-3}\right)$ represented the equilibrium concentration and $q_{e}\left(\mathrm{mgg}^{-1}\right)$ the equilibrium amount of solute.

A straight-line plot of $C_{e} / q_{e}$ against $C_{e}$ (Figure 6a) estimated $Q_{\max }$ as reciprocal of the slope and $b$ as the ratio of the slope and the intercept (Table 4).

The nature of adsorption may be evaluated from separation factor, a dimensionless quantity, $R_{L}$, expressed as,

$$
R_{L}=\frac{1}{1+b \cdot C_{0}}
$$

where, $\mathrm{b}$ was the Langmuir constant and $\mathrm{C}_{0}$ the initial ARS concentration in solution

The value of separation factor $\left(R_{L}\right)$ revealed important information about the nature of adsorption such as, irreversible $\left(R_{L}=0\right)$, favorable $\left(0<R_{L}<1\right)$, linear $\left(R_{L}=1\right)$ and unfavorable $\left(R_{L}>1\right)$. The separation factor $\left(R_{L}\right)$ in the present study was found to be in the range $0<R_{L}<1$, indicating a favorable case of adsorption in the present soluteadsorbent system [35]. The evaluated constants were given in Table 5. It was found that both $Q_{\max }$ and b values increased with temperature.

\subsubsection{Freundlich isotherm}

Freundlich isotherm model assumed that the adsorption sites (surface of FeCNB) were made up of small heterogeneous layers and the non-ideal adsorption took place on such surfaces [36]. In the linear form it was expressed as,

$$
\ln q_{e}=\ln K_{F}+\frac{1}{n} \ln C_{e}
$$

where, $K_{F}$ represented Freundlich isotherm constant related to adsorption capacity $\left(\mathrm{gmg}^{-1}\right)\left(\mathrm{mgdm}^{-3}\right)^{-1 / \mathrm{n}}$ and $1 / \mathrm{n}$ represented adsorption intensity.

The value $K_{F}$ and $1 / n$ were calculated from the slope and intercept of the linear plot $\ln q_{e}$ against $\ln C_{e}$ (Figure $6 \mathrm{~b}$ ). The Freundlich constants $K_{F}$ increased with temperature. Although $1 / \mathrm{n}$ did not follow a definite trend, the value $1 / n<1$ at each case (Table 4) indicated a favorable adsorption condition.

\subsubsection{Tempkin isotherm}

Tempkin isotherm assumed that the free energy of interaction between the adsorbate and the adsorbent was a function of the surface coverage [37]. It may be represented as, 


$$
q_{e}=\left(\frac{R T}{B_{T}}\right) \ln A_{T}+\left(\frac{R T}{B_{T}}\right) \ln C_{e}
$$

where, $B_{T}\left(\mathrm{kJmol}^{-1}\right)$ was represented the heat of adsorption and $A_{T}\left(\mathrm{dm}^{3} \mathrm{mg}^{-1}\right)$ was the equilibrium binding constant corresponding to the maximum binding energy.

A plot of $q_{e}$ against $\ln C_{e}$ yielded a straight line (Figure 6c). The constants $A_{T}$ and $B_{T}$ were evaluated from the slope and the intercept of the straight line. The values of $A_{T}$ and $B_{T}$ were presented in Table 4.

The equilibrium data fit to the isotherm models revealed that the values of coefficient of determination $\left(R^{2}\right)$ followed the order Langmuir $>$ Tempkin $>$ Freundlich for all the temperatures. Moreover, the values of standard error (SE) were much lower in case of the Langmuir than the Tempkin and the Freundlich model. Therefore, the Langmuir model best represented the ARS-FeCNB interaction in the present case.

\subsubsection{Dubinin-Radushkevich isotherm}

In an aim to describe mechanistic pathway for the adsorption process, the Dubinin-Radushkevich (D-R) isotherm model was tested. It was based on the heterogeneity of the adsorbent surface and follows the concept of Polynyi potential $(C)$ [38]. The linear form of the D-R isotherm was presented as,

$$
\ln q_{e}=\ln q_{s}-K_{a d} \epsilon^{2}
$$

where, $q_{s}$ was maximum adsorption capacity $\left(\mathrm{mgg}^{-1}\right), K_{a d}$ was D-R isotherm constant $\left(\mathrm{mol}^{2} \mathrm{~J}^{-2}\right)$ related to adsorption energy and $C$ was expressed as,

$$
C=R T \ln \left(1+\frac{1}{C_{e}}\right)
$$

The parameters $q_{s}$ and $K_{a d}$ were obtained from the intercept and slope respectively of the straight line of plot of $\ln q_{e}$ against $\epsilon^{2}$ (Figure 6d).

The mean free energy of adsorption $E$, defined as the free energy change when one mole of solute was transferred to the surface of the solid from infinite in solution can be calculated from $K_{a d}$ from the following equation.

$$
E=\left(-2 K_{a d}\right)^{-\frac{1}{2}}
$$

The D-R parameters and mean free energy were given in Table 4. The magnitude of $E$ was used for evaluating the type of solute-adsorbent interaction. It was estimated that in case of $E>8 \mathrm{kJmol}^{-1}$, the interaction was aided by intraparticle diffusion, for $E$ value in the range of $8-16 \mathrm{kJmol}^{-1}$ the process was mainly through ion exchange and for $E$ $<8 \mathrm{kJmol}^{-1}$ the interaction was predominately electrostatic in nature [39]. In the present case the $E$ value was found to be less than $8 \mathrm{kJmol}^{-1}$ at all the studied temperatures, indicating that the retention of ARS on to FeCNB occured through electrostatic interaction. Moreover, the $E$ value decreased with an increase in temperature. Thus, retention of ARS on to FeCNB was favored at higher temperature. 
Table 4. Isotherm parameters

\begin{tabular}{|c|c|c|c|c|c|}
\hline Model & $\mathrm{T}(\mathrm{K})$ & $\mathrm{b}\left(\mathrm{dm}^{3} \mathrm{mg}^{-1}\right)$ & $\mathrm{Q}_{\max } \cdot 10^{-2}\left(\mathrm{mgg}^{-1}\right)$ & $\mathrm{R}^{2}$ & SE \\
\hline \multirow[t]{3}{*}{ Langmuir } & 290 & 0.1298 & 1.519 & 0.9991 & 0.0256 \\
\hline & 300 & 0.5310 & 1.669 & 0.9990 & 0.0241 \\
\hline & 310 & 0.5436 & 1.957 & 0.9984 & 0.0312 \\
\hline \multirow[t]{4}{*}{ Freundlich } & $\mathrm{T}(\mathrm{K})$ & $1 / \mathrm{n}$ & $\mathrm{K}_{\mathrm{F} \cdot} \cdot 10^{-2}\left(\mathrm{gmg}^{-1}\right)\left(\mathrm{mgdm}^{-3}\right)^{-1 / n}$ & $\mathrm{R}^{2}$ & SE \\
\hline & 290 & 0.3552 & 0.3370 & 0.9742 & 2.320 \\
\hline & 300 & 0.2713 & 0.6491 & 0.9581 & 1.989 \\
\hline & 310 & 0.3524 & 0.6943 & 0.9590 & 2.412 \\
\hline \multirow[t]{4}{*}{ Tempkin } & $\mathrm{T}(\mathrm{K})$ & $\mathrm{B}_{\mathrm{T}}\left(\mathrm{kJgmg}^{-1} \mathrm{~mol}^{-1}\right)$ & $\mathrm{A}_{\mathrm{T}} \cdot 10^{-2}\left(\mathrm{dm}^{3} \mathrm{mg}^{-1}\right)$ & $\mathrm{R}^{2}$ & SE \\
\hline & 290 & 8.118 & 1.645 & 0.9853 & 1.321 \\
\hline & 300 & 9.705 & 14.48 & 0.9834 & 1.024 \\
\hline & 310 & 7.179 & 8.033 & 0.9862 & 1.847 \\
\hline \multirow{4}{*}{$\begin{array}{c}\text { Dubinin- } \\
\text { Radushkevich }\end{array}$} & $\mathrm{T}(\mathrm{K})$ & $\mathrm{K}_{\mathrm{ad}} \cdot 10^{7}\left(\mathrm{~mol}^{2} \mathrm{~kJ}^{-2}\right)$ & $\mathrm{q}_{\mathrm{s}} \cdot 10^{-2}\left(\mathrm{mgg}^{-1}\right)$ & $\mathrm{E}\left(\mathrm{kJmol}^{-1}\right)$ & $\mathrm{R}^{2}$ \\
\hline & 290 & 2.110 & 1.166 & 7.071 & 0.8954 \\
\hline & 300 & 1.842 & 1.328 & 1.041 & 0.8811 \\
\hline & 310 & 0.1412 & 1.462 & 0.3162 & 0.8882 \\
\hline
\end{tabular}

* evaluated data presented in 4 significant digits

Table 5. Separation factor $\left(R_{L}\right)$

\begin{tabular}{cccc}
\hline & \multicolumn{3}{c}{$\mathrm{R}_{\mathrm{L}}$} \\
\cline { 2 - 4 } $\mathrm{T}(\mathrm{K})$ & $\mathrm{C}_{0}\left(\mathrm{mgdm}^{-3}\right)$ & $\mathrm{C}_{0}\left(\mathrm{mgdm}^{-3}\right)$ & $\mathrm{C}_{0}\left(\mathrm{mgdm}^{-3}\right)$ \\
& 50 & 100 & 150 \\
\hline 290 & 0.1334 & 0.0714 & 0.0488 \\
300 & 0.0362 & 0.0184 & 0.0123 \\
310 & 0.0354 & 0.0180 & 0.0121 \\
\hline
\end{tabular}

* evaluated data presented in 4 significant digits

\subsection{Thermodynamic study}

The adsorption spontaneity was illustrated from the thermodynamic parameters such as enthalpy $\left(\Delta H^{\circ}\right)$, entropy $\left(\Delta S^{\circ}\right)$ and free energy $\left(\Delta G^{\circ}\right)$ using the following equations [40].

$$
\begin{gathered}
\Delta G^{\circ}=R T \ln K_{C} \\
R \ln K_{C}=\Delta S^{\circ}-\frac{\Delta H^{\circ}}{T}
\end{gathered}
$$

where, $K_{C}$ is the equilibrium constant, $R$ was the universal gas constant $\left(8.314 \mathrm{Jmol}^{-1} \mathrm{~K}^{-1}\right)$ and $T$ was the absolute temperature in Kelvin scale.

A straight-line plot of $\mathrm{RlnK}_{\mathrm{c}}$ against $1 / \mathrm{T}$ (Figure 6e) yielded $\Delta \mathrm{H}^{\circ}$ from the slope and $\Delta \mathrm{S}^{\circ}$ from the intercept (Table 6). It was found that the values of $\Delta G^{\circ}$ for all the temperatures are negative indicating a case of spontaneous adsorption. The 
$\Delta H^{\circ}$ value was found to be positive indicating endothermic nature and thus the extent of retention was found to increase with temperature. The positive value of $\Delta S^{\circ}$ implied a favorable process due to increased randomness at the solidsolution interface [41] during ARS-FeCNB interaction.
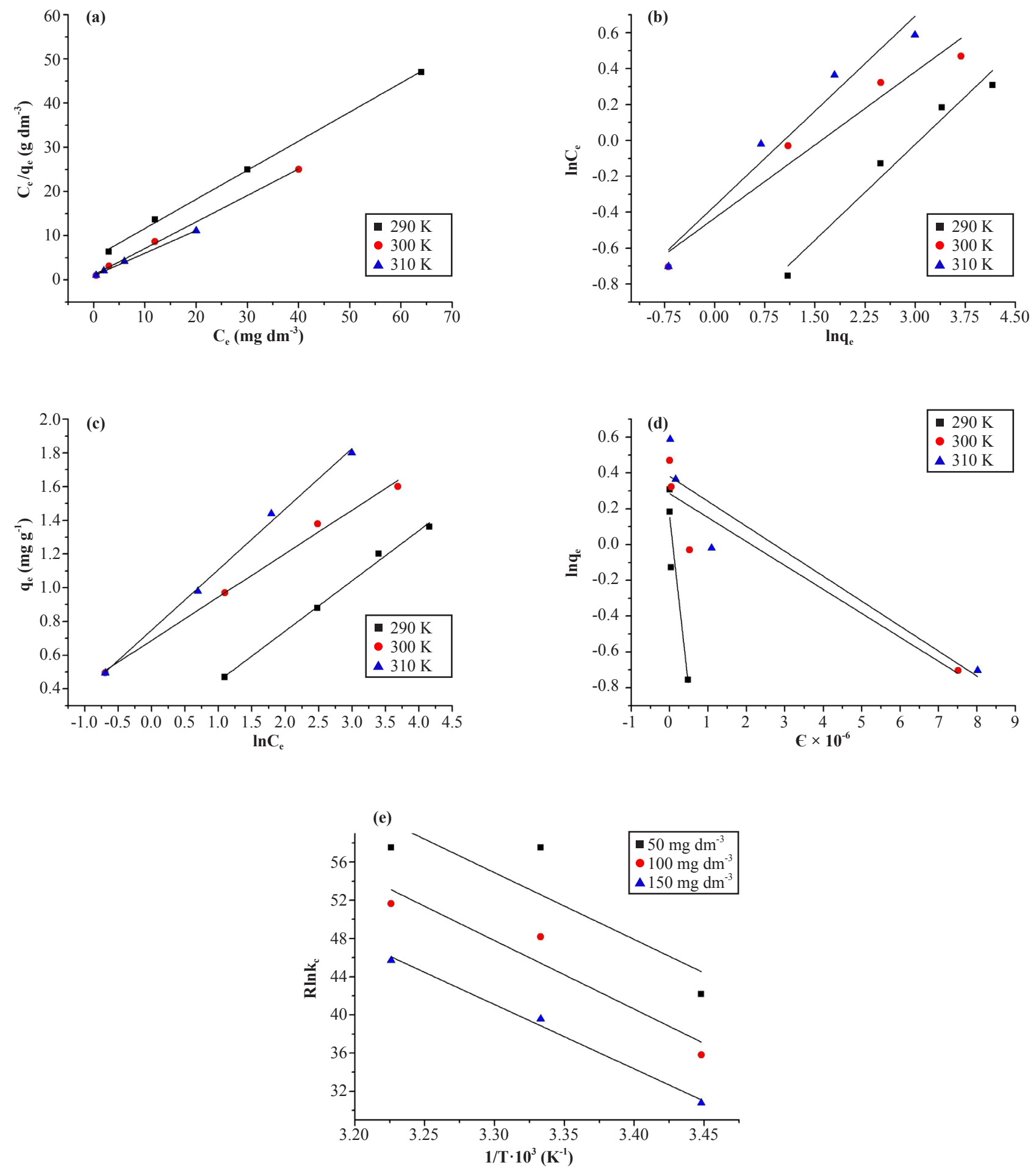

Figure 6. Plot of (a) Langmuir isotherm (b) Freundlich isotherm (c) Tempkin isotherm (d) Dubinin-Radushkevich isotherm (e) Van't Hoff equation 
Table 6. Thermodynamic parameters

\begin{tabular}{ccccc}
\hline Conc. $\left(\mathrm{mgdm}^{-3}\right)$ & $\mathrm{T}(\mathrm{K})$ & $-\Delta \mathrm{G}^{\circ}\left(\mathrm{kJmol}^{-1}\right)$ & $\Delta \mathrm{H}^{\circ}\left(\mathrm{kJmol}^{-1}\right)$ & $\Delta \mathrm{S}^{\circ}\left(\mathrm{Jmol}^{-1} \mathrm{~K}^{-1}\right)$ \\
\hline \multirow{2}{*}{100} & 290 & 35.82 & & \\
& 300 & 48.19 & 71.62 & 0.284 \\
& 310 & 51.66 & & \\
\hline
\end{tabular}

*evaluated data presented in 4 significant digits

\subsection{Kinetic study}

The adsorption rate for the present solute-adsorbent interaction was evaluated comparing pseudo first order (Lagergren) and pseudo second order models for three different concentrations (50, 100, $\left.150 \mathrm{mgdm}^{-3}\right)$ at temperature $300 \mathrm{~K}$.

\subsubsection{Pseudo-first order model (Lagergren)}

The Lagergren or pseudo first-order rate equation [42] in linear form was expressed as,

$$
\ln \left(q_{e}-q_{t}\right)=\ln q_{e}-K_{1} t
$$

where, $\mathrm{q}_{\mathrm{e}}$ was the amount of dye adsorbed $\left(\mathrm{mgg}^{-1}\right)$ at equilibrium and $q_{t}$ was that at time $\mathrm{t}$ (min.).

A plot of $\ln \left(q_{e}-q_{t}\right)$ against time (t) (Figure 7a) yielded a straight line and the Lagergren rate constant $K_{1}$ was obtained from the slope of the plot. It was found that rate constant $\left(K_{1}\right)$ decreased with increase of concentration (Table 7).

\subsubsection{Pseudo second order model}

The linear form of pseudo second order rate model [43] was represented as,

$$
\frac{t}{q_{t}}=\frac{1}{K_{2} q_{e}^{2}}+\frac{t}{q_{e}}
$$

where, $K_{2}$ was the second order rate constant $\left(\mathrm{gmg}^{-1} \mathrm{~min}^{-1}\right)$ that can be estimated from the intercept of the linear plot of $t /$ $q_{t}$ against time (Figure $7 \mathrm{~b}$ ). With increase in dye concentration the second order rate constant was found to decrease (Table 7).

Comparing the above two kinetic models, it was found that values of coefficient of determination $\left(R^{2}\right)$ was comparatively higher in the second-order rate equation than that of the first order rate equation. The standard error (SE) was much less for each dye concentration in the second order than the first order model. Thus, the pseudo second order model was suggested to be better fit for the ARS-FeCNB interaction.

\subsubsection{Intraparticle diffusion model (Weber-Morris)}

The kinetic results were also analyzed for the Weber-Morris or intraparticle diffusion model [44], represented as,

$$
q_{t}=K_{p} t^{\frac{1}{2}}+C
$$

where, $C\left(\mathrm{mgg}^{-1}\right)$ was the intercept and $K_{P}\left(\mathrm{mgg}^{-1} \mathrm{~min}^{-1 / 2}\right)$ was the intraparticle diffusion rate constant.

The Weber and Morris plot (Figure 7c) revealed an initial curved portion (indicative of boundary layer effect, 
i.e. surface adherence) followed by a linear portion (indicative of intraparticle or pore diffusion). The slope of the linear portion yielded $K_{P}$, while the intercept signified the extent of boundary layer effect. The larger the intercept the greater the contribution to the surface adherence [45] in the rate limiting step. It was found that $K_{P}$ value increased with temperature (Table 7). The activation energy $(E)$ of the pore diffusion was calculated from the linear plot of $\ln K_{P}$ against 1/T following Arrhenius equation:

$$
\ln K_{p}=\ln A-\frac{E}{R T}
$$

The goodness of the data fit was indicated by the high regression coefficient $\left(\mathrm{R}^{2}=0.9685\right)$ value of the Arrhenius plot (Figure 7d) and the $E$ value was found to be $56.77 \mathrm{Jmol}^{-1}$.

(a)

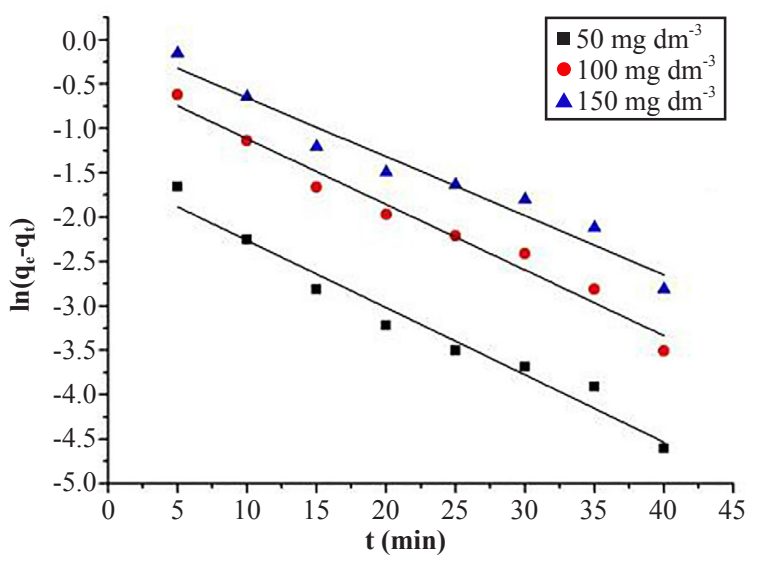

(c)

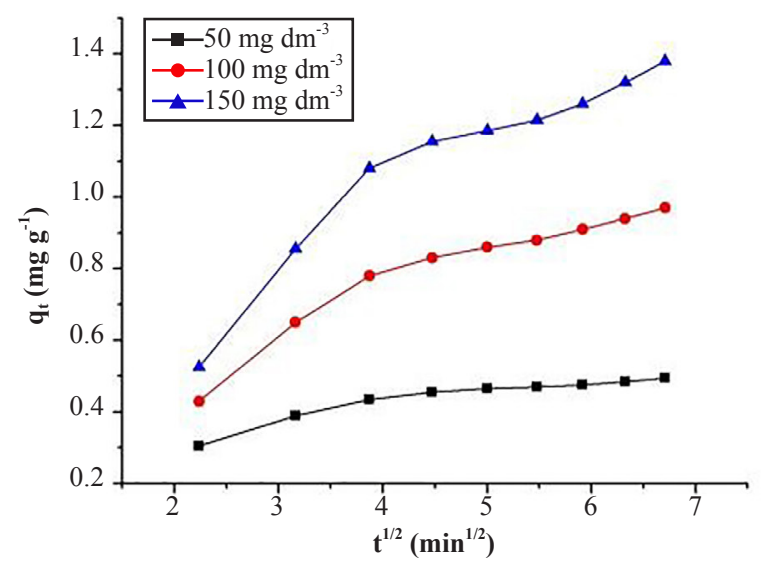

(b)

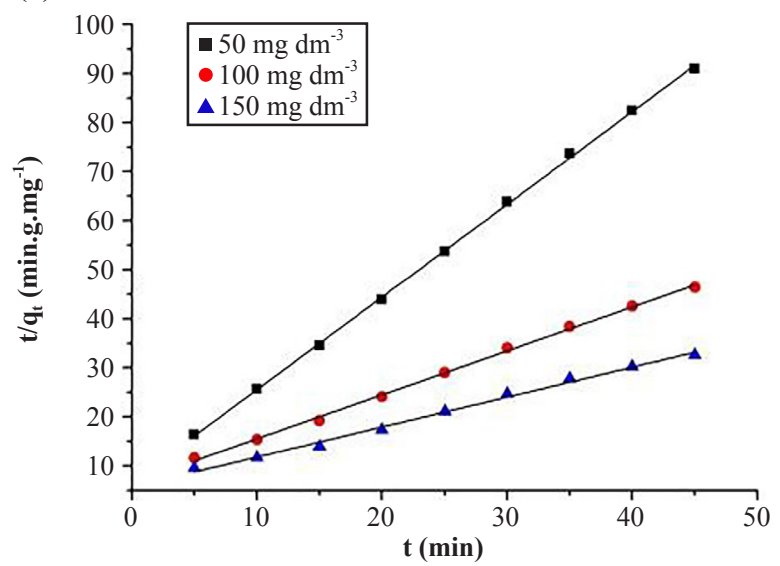

(d)

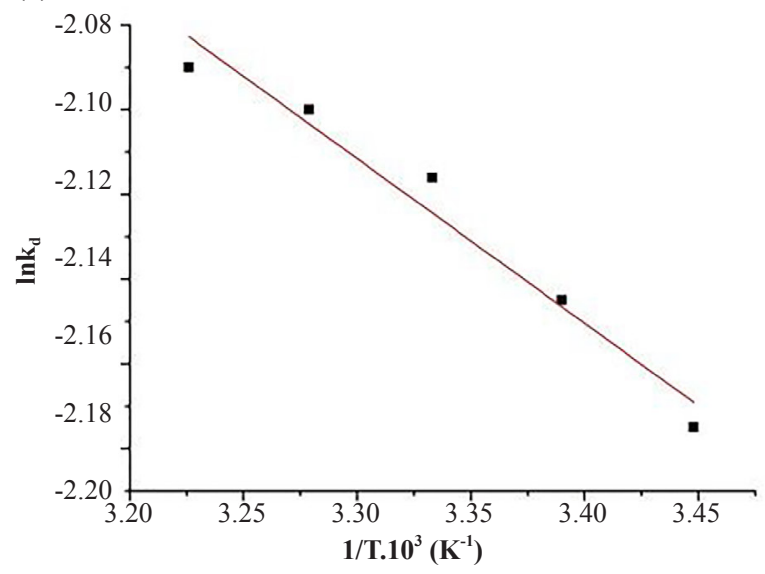

Figure 7. Plot of (a) First order (b) Second order kinetic equation (c) Intraparticle diffusion model (Weber-Morris) (d) Arrhenius equation 
Table 7. Kinetic parameters

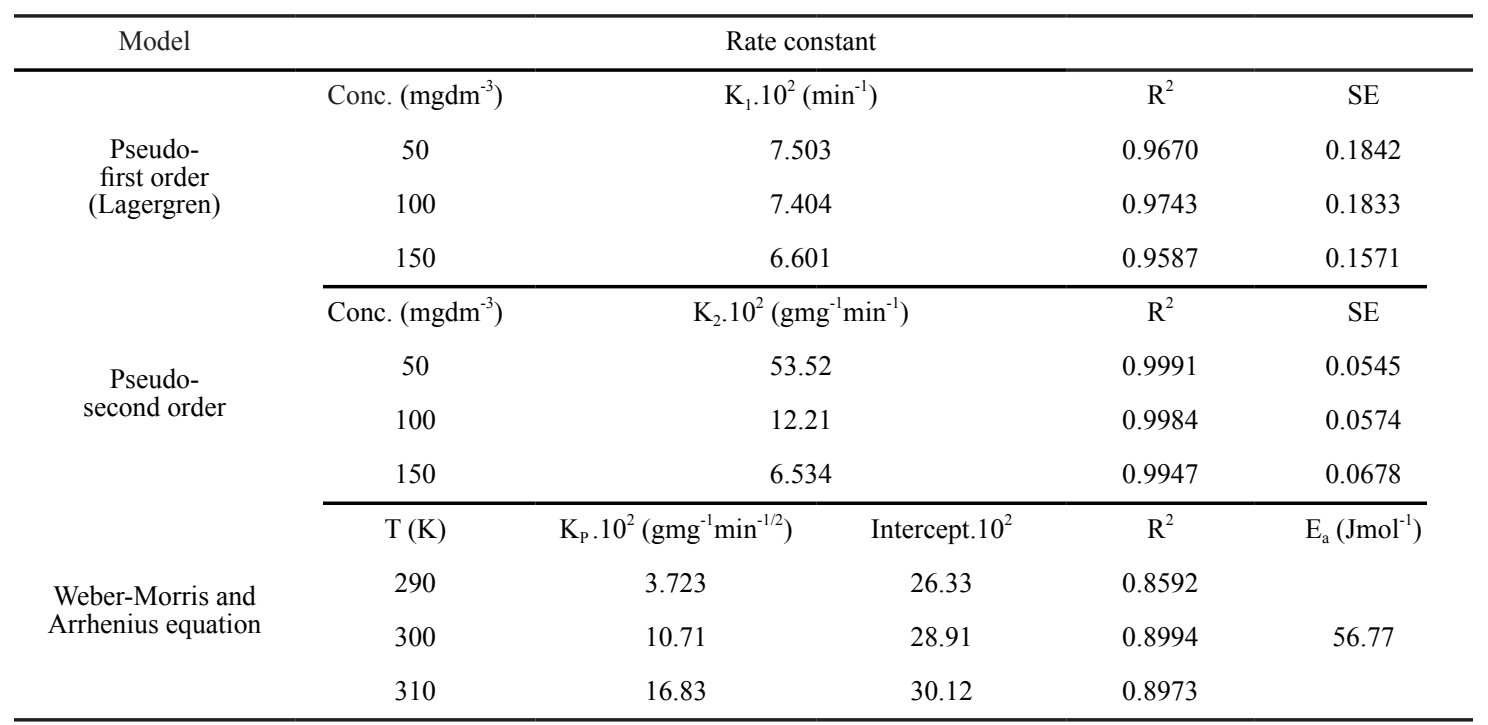

*evaluated data presented in 4 significant digits

\subsection{Mechanism of ARS-FeCNB interaction}

A comparison of the adsorption efficiency of $\mathrm{CNB}$ and $\mathrm{FeCNB}$ indicated that under similar condition the former yielded poor ARS adsorption (Figure 8a). Under optimum equilibrium condition the Langmuir isotherm model was most suited than the Tempkin and the Freundlich model. The evaluation of adsorption energy $\left(<8 \mathrm{kJmol}^{-1}\right)$ from the DubininRadushkevich isotherm model suggested that ARS-FeCNB interaction was predominantly electrostatic in nature. The electrostatic interaction between the anionic dye and cationic adsorbent surface can be explained by the $\mathrm{pH}_{\mathrm{ZPC}}$ of FeCNB. Such phenomenon can further be supported from the enthalphy $\left(\Delta \mathrm{H}^{\circ}\right)$ of ARS-FeCNB interaction. Based on the value of $\Delta \mathrm{H}^{\circ}\left(20 \leq \Delta \mathrm{H}^{\circ} \leq 80 \mathrm{kJmol}^{-1}\right)$ the ARS-FeCNB interactions may be said to be as electrostatic in nature [46]. The value of $\Delta \mathrm{S}^{\circ}$ was found to be positive during the dye-nanocomposite bead interaction. It may be thought that the solute was displaced from the aqueous phase when it was adsorbed onto the solid phase, thereby enhancing the enthalpy value.

The kinetic data best fitted to the pseudo second order model compared to the pseudo first order model supports the chemisorptions process. Thus, the adsorption proceeds via electrostatic interaction [12]. The adsorption capacities of some iron based materials such as activated carbon $/ \gamma-\mathrm{Fe}_{2} \mathrm{O}_{3}$ nano-composite (108.69 $\mathrm{mgg}^{-1}$ [12], $\mathrm{NiFe}_{2} \mathrm{O}_{4} /$ polyaniline magnetic composite $\left(186 \mathrm{mgg}^{-1}\right)$ [13], polypyrrole coated $\mathrm{Fe}_{3} \mathrm{O}_{4}$ nanoparticles (116.6 $\left.\mathrm{mgg}^{-1}\right)$ [14], activated clay modified by iron oxide (32.70 mgg $\mathrm{mg}^{-1}$ [15], magnetic nanoparticles of $\mathrm{Fe}_{3} \mathrm{O}_{4}\left(140.8 \mathrm{mgg}^{-1}\right), \mathrm{CoFe}_{2} \mathrm{O}_{4}\left(192.3 \mathrm{mgg}^{-1}\right)$, and IL- $\mathrm{Fe}_{3} \mathrm{O}_{4}$ $\left(256.4 \mathrm{mgg}^{-1}\right)$ [16] were compared with that of $\mathrm{FeCNB}\left(166.9 \mathrm{mgg}^{-1}\right)$, in the present report. A somewhat high capacity of $\mathrm{NiFe}_{2} \mathrm{O}_{4}$ /polyaniline magnetic composite [13], $\mathrm{CoFe}_{2} \mathrm{O}_{4}$, and $\mathrm{IL}-\mathrm{Fe}_{3} \mathrm{O}_{4}$ [16] may be due to higher equilibration time, temperature or lower ARS concentration range. Thus, the present synthesized nanocomposite is more efficient for ARS adsorption in terms of higher capacity in lower equilibrium time and temperature and higher ARS concentration range.

\subsection{Desorption study}

Desorption study was performed to test the reusability of FeCNB.

\subsubsection{Choice of eluent}

Desorption of ARS was carried out using aqueous $\mathrm{NaOH}$ solution with different concentrations $\left(1.0 \times 10^{-2}\right.$ $\left.100.0 \times 10^{-2} \mathrm{M}\right)$. Regeneration study of FeCNB via desorption of ARS is very important in the context of reusability 
of the adsorbent. Eluting reagent was selected first and then reusability test was performed. Elution of ARS was found effective using $10.0 \times 10^{-2} \mathrm{M} \mathrm{NaOH}$ and almost $98 \%$ of adsorbed ARS was desorbed.

\subsubsection{Regeneration and reusability of $\mathrm{FeCNB}$}

FeCNB after regeneration using $10.0 \times 10^{-2} \mathrm{M} \mathrm{NaOH}$ may be recycled for retention of ARS at least for three successive operations maintaining its retention ability. The retention extent decreased to $92 \%$ after five cycles. The retention of ARS was found to decrease to $86 \%$ after 3 cycles and $66 \%$ after 5 cycles using $5.0 \times 10^{-2} \mathrm{M} \mathrm{NaOH}$. Using $50.0 \times 10^{-2} \mathrm{M} \mathrm{NaOH}$ the retention decreased to $77 \%$ after 3 cycles and $59 \%$ after 5 cycles (Figure $8 \mathrm{~b}$ ). In order to explain such observations the stability aspect of $\mathrm{FeCNB}$ (possible iron leaching) versus ARS retention with $\mathrm{NaOH}$ strength (Figure 8c) was studied. It was found that with increased $\mathrm{NaOH}$ strength the extent of iron leaching was increased. The extent of iron leaching was found to be 9,12 and $34 \%$ using $5.0 \times 10^{-2}, 10.0 \times 10^{-2}$ and $50.0 \times 10^{-2}(\mathrm{M})$ $\mathrm{NaOH}$ respectively. Thus, lower retention using $0.05 \mathrm{M} \mathrm{NaOH}$ may be due to lower desorption ability while that using $50.0 \times 10^{-2} \mathrm{M} \mathrm{NaOH}$ may be due to stability loss of FeCNB.
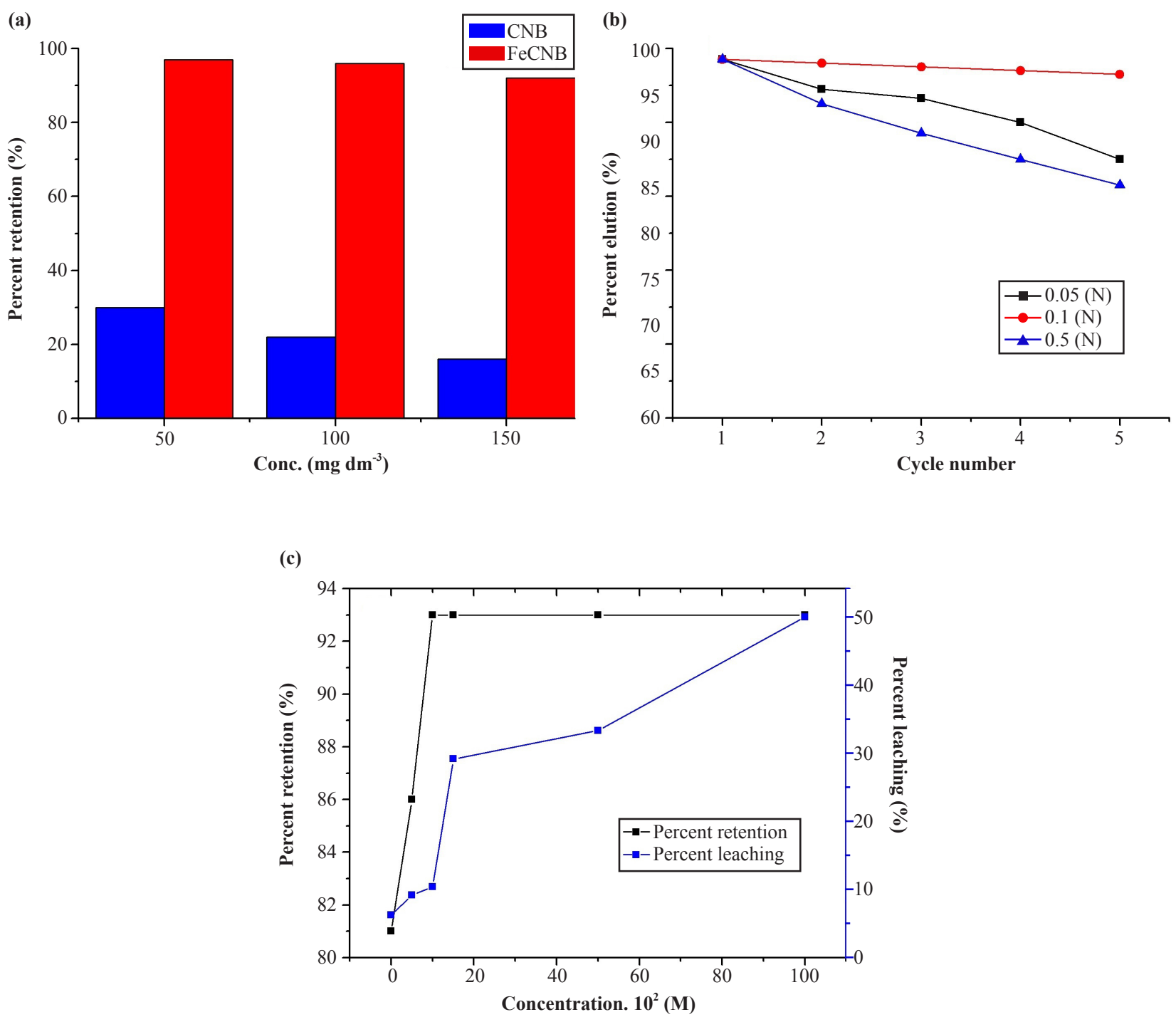

Figure 8. (a) Adsorption efficiency of CNB and FeCNB (b) Recycling of FeCNB and (c) ARS elution and Fe(III) leaching 


\section{Conclusions}

Iron(III) modified cellulose nanocomposite bead (FeCNB) was found to be very much effective and suitable adsorbent for the removal of alizarin red $\mathrm{S}$ from aquatic environment. The process was optimized for the multi variables, mutually interactive and cooperative, influencing the adsorption of ARS on FeCNB. Factorial design was used primarily to categorize the significant variables. Central composite design was applied to build the mathematical function (polynomial) correlating variables and the response (adsorption percent). The model validity as well as the data quality was established from ANOVA. The maximum adsorption capacity was obtained around pH 3-6. Adsorption was increased with the increase in the dose, contact time and temperature, and decrease in the initial concentration. A maximum adsorption of $97 \%$ was observed at $\mathrm{pH} 3.0$, shaking time of 45 mins and dose of $2.0 \mathrm{gdm}^{-3}$ corresponding to an initial dye concentration of $100 \mathrm{mgdm}^{-3}$ at $300 \mathrm{~K}$. The process followed the Langmuir isotherm and pseudo second order rate model, as evaluated from the values of regression coefficient and standard error. The process was thermodynamically feasible, endothermic and favorable. The $\Delta \mathrm{G}^{\circ}$ value was found negative $\left(-48.19 \mathrm{kJmol}^{-1}\right)$, and $\Delta \mathrm{H}^{\circ}$ $\left(71.62 \mathrm{kJmol}^{-1}\right)$ as well as $\Delta \mathrm{S}^{\circ}\left(0.284 \mathrm{Jmol}^{-1} \mathrm{~K}^{-1}\right)$ values were positive. The $\mathrm{R}_{\mathrm{L}}$ value predicted the feasibility of this process. The mean free energy of adsorption $\left(1.041 \mathrm{kJmol}^{-1}\right.$ at $\left.300 \mathrm{~K}\right)$ implied that ARS FeCNB interaction was physical in nature. Desorption experiment showed that the percentage of ARS removed and adsorbent regenerated increase with increase of $\mathrm{pH}$ and strength of regeneration solution. $\mathrm{NaOH}\left(1.0 \cdot 10^{-1} \mathrm{~N}\right)$ was found to be most effective and suitable regeneration solution. FeCNB can be regenerated and reused at least for 5 cycles of adsorption/desorption process. The literature data revealed that $\mathrm{FeCNB}$ is effective and efficient than some similar reported adsorbents in terms of simple preparation and operation, capacity, stability, renewability and cost.

\section{Acknowledgements}

The authors sincerely acknowledge the University of Kalyani for providing the laboratory and infrastructural facilities. The assistance and instrumental facilities received under UGC-SAP, DST-FIST and DST-PURSE are duly acknowledged. Authors are thankful to IACS, Kolkata for providing instrumental facilities.

\section{Compliance with ethical standards}

Conflict of interest: The authors declare that they have no conflict of interest.

\section{References}

[1] Ran Y, Dawei L, Aimin L and Hu Y. Adsorption properties and mechanisms of palygorskite for removal of various ionic dyes from water. Applied Clay Science. 2018; 151: 20-28.

[2] Fayazi M, Afzali D, Taher MA, Mostafavi A and Gupta VK. Removal of safranin dye from aqueous solution using magnetic mesoporous clay: Optimization study. Journal of Molecular Liquids. 2015; 212: 675-685.

[3] Guzel F, Saygili H, Saygili GA and Koyuncu F. Elimination of anionic dye by using nanoporous carbon prepared from an industrial biowaste. Journal of Molecular Liquids. 2014; 194: 130-140.

[4] Zucca P, Vinci C, Sollai F, Rescigno A and Sanjust E. Degradation of alizarin red S under mild experimental conditions by immobilized 5,10,15,20-tetrakis $\mathrm{N}$ (4-sulfonatophenyl) porphine-Mn(III) as a biomimetic peroxidise like catalyst. Journal of Molecular Catalysis. 2008; 288: 97-102.

[5] Srivastava V, Sillanpaa M. Synthesis of malachite@clay nanocomposite for rapid scavenging of cationic and anionic dyes from synthetic wastewater. Journal of Environmental Science. 2017; 51: 97-110.

[6] Hanif S, Shahzad A. Removal of chromium (VI) and dye alizarin red S (ARS) using polymer coated iron oxide $\left(\mathrm{Fe}_{3} \mathrm{O}_{4}\right)$ magnetic nanoparticles by co-precipitation method. Journal of Nanoparticle Research. 2014; 16: 2429. Available from: doi: 10.1007/s11051-014-2429-8.

[7] Adeogun AI, Balakrishnan RB. Electrocoagulation removal of anthraquinone dye alizarin red S from aqueous 
solution using aluminum electrodes: kinetics, isothermal and thermodynamics studies. Journal of Electrochemical Science and Engineering. 2016; 6: 199-213.

[8] Joshi KM, Shrivastava VS. Degradation of alizarine red S (a textiles dye) by photocatalysis using $\mathrm{ZnO}_{\text {and }} \mathrm{TiO}_{2}$ as photocatalyst. International Journal of Environmental Sciences. 2011; 2: 8-21.

[9] Abou-Gamra ZM. Kinetics of decolorization of alizarin red S in aqueous media by Fenton like mechanism. European Chemical Bulletin. 2014; 3: 108-112.

[10] Hynes NRJ, Kumar JS, Kamyab H, Sujana JAJ, Al-Khashman OA, Kuslu Y, et al. Modern enabling techniques and adsorbents based dye removal with sustainability concerns in textile industrial sector-A comprehensive review. Journal of Cleaner Production. 2020; 272 : 122636. Available from: https://doi.org/ 10.1016/ j.jclepro.2020.122636.

[11] Sarkar M, Sarkar S. Adsorption of Cr(VI) on iron(III) cellulose nanocomposite bead. Environmental Processes. 2017; 4: 551-571.

[12] Fayazi M, Ghanei-Motlagh M, Taher MI. The adsorption of basic dye (alizarin red S) from aqueous solution onto activated carbon $/ \gamma-\mathrm{Fe}_{2} \mathrm{O}_{3}$ nano-composite: Kinetic and equilibrium studies. Material Science in Semiconductor Processing. 2015; 40: 35-43.

[13] Liang Y, He Y, Zhang Zhu Q, Adsorption property of alizarin red S by $\mathrm{NiFe}_{2} \mathrm{O}_{4}$ /polyaniline magnetic composite. Journal of Environmental Chemical Engineering. 2018; 6: 416-425.

[14] Gholivand MB, Yamini Y, Dayeni M, Seidi S and Tahmasebi E. Adsorptive removal of alizarin red S and alizarin yellow GG from aqueous solutions using polypyrrole-coated magnetic nanoparticles. Journal of Environmental Chemical Engineering. 2015; 3(1): 529-540. Available from: http://dx.doi.org/10.1016/j.jece.2015.01.011.

[15] Fu F, Gao Z, Gao L and Li D. Effective adsorption of anionic dye, alizarin red S from aqueous solutions on activated clay modified by iron oxide. Industrial \& Engineering Chemistry Research. 2011; 50: 9712-9717.

[16] Kamran S, Shiri NA. A comparative study for adsorption of alizarin red S from aqueous samples by magnetic nanoparticles of $\mathrm{Fe}_{3} \mathrm{O}_{4}, \mathrm{CoFe}_{2} \mathrm{O}_{4}$ and ionic liquid modified $\mathrm{Fe}_{3} \mathrm{O}_{4}$. Chemical Methodologies. 2018; 2: 23-38.

[17] Santra D, Joarder R, Sarkar M. Taguchi design and equilibrium modeling for fluoride adsorption on cerium loaded cellulose nanocomposite bead. Carbohydrate Polymer. 2014; 111: 813-821.

[18] Arenas LT, Lima EC, Santos AAD, Vaghetti JCP, Coasta TMH and Benvenutti EV. Use of statistical design of experiments to evaluate the sorption capacity of 1,4-diazoniabicycle [2,2,2] octane silica chloride for Cr(VI) adsorption. Colloid and Surfaces A Physiochemical and Engineering Aspects. 2006; 297: 240-248.

[19] Montgomery DC. Design and analysis of experiments. 4th ed. New York: Wiley; 1997. p.1-26.

[20] Ani JU, Nnaji NJ, Okoye COB and Onukwuli OD. Factorial analyses, equilibrium studies, kinetics and thermodynamics of the removal of suspended particles from an industrial effluent on coal based activated carbon. International Journal of Chemical Sciences. 2012; 10(3): 1765-1784.

[21] Fan M, Dai D, Huang B. Fourier transform infrared spectroscopy for natural fibres. In: Salih S. (ed.) Fourier Transform Materials. 2012. p.45-68. Available from: doi: 10.5772/35482.

[22] Moriguchi T, Yano K, Nakagawa S and Kaji F. Elucidation of adsorption mechanism of bone-staining agent alizarin red S on hydroxyapatite by FT-IR micro spectroscopy. Journal of Colloid Interface Science. 2003; 260: 19-25.

[23] Stoica-Guzun A, Stroescu M, Jinga SI, Mihalache N, Botez A, Matei C, et al. Box-Behnken experimental design for chromium (VI) ions removal by bacterial cellulose-magnetite composites. International Journal of Biological Macromolecules. 2016; 9: 11062-11072.

[24] Ansari F, Galland S, Johansson M, Plummer CJG and Berglund LA. Cellulose nanofiber network for moisture stable, strong and ductile biocomposites and increased epoxy curing rate. Composites Part A. 2014; 63: 35-44.

[25] Tchuifon DR, Anaghoa SG, Njanja E, Ghogomu JN, Ndifor-Angwafor NG and Kamgaing T. Equilibrium and kinetic modelling of methyl orange adsorption from aqueous solution using rice husk and Egussi peeling. International Journal of Chemical Sciences. 2014; 12: 741-761.

[26] Belay K, Hayelom A. Removal of methyl orange from aqueous solutions using thermally treated egg shell (locally available and low cost biosorbent). Chemistry and Materials Research. 2014; 6: 31-39.

[27] Asiagwu AK, Peretomo-Clarke BO, Okposo MA. Sorption kinetics for the removal of methyl violet dye from waste water using African nutmeg as biomass. Journal of Chemical Biological and Phyical Sciences. 2017; 7: 97106.

[28] Kaur H, Kaur S, Kaur R. Kinetic and isotherm studies of congo red adsorption from aqueous solution by biowaste material. Chemcal Science Transactions. 2014; 3: 1300-1309.

[29] Candoti LV, Robles JC, Mantovani VE and Goicoechea HC. Multiple response optimization applied to the of a capillary electrophoretic method for pharmaceutical analysis. Talanta. 2006; 69: 140-147.

[30] Dil EA, Ghaedi M, Ghaedi AM, Asfaram A, Goudarz A, Hajati S, et al. Modeling of quaternary dyes adsorption onto ZnO-NR-AC artificial neural network: Analysis by derivative spectrophotometry. Journal of Industrial and 
Engineering Chemistry. 2015; 2724: 1-11.

[31] Asfaram A, Ghaedi M, Goudarzi A and Rajabi M. Response surface methodology approach for optimization of simultaneous dye and metal ion ultrasound-assisted adsorption onto $\mathrm{Mn}$ doped $\mathrm{Fe}_{3} \mathrm{O}_{4}$ - $\mathrm{NPs}$ loaded on AC: kinetic and isothermal studies. Dalton Transactions. 2015; 44: 14707-14723.

[32] Adesola B, Ogundipe K, Sangosanya KT, Akintola BD, Oluwa A and Hassan E. Comparative study on the biosorption of $\mathrm{Pb}(\mathrm{II}), \mathrm{Cd}(\mathrm{II})$ and $\mathrm{Zn}$ (II) using Lemon grass (Cymbopogon citratus): kinetics, isotherms and thermodynamics. Chemistry International. 2016; 2: 89-102.

[33] Iqbal M, Iqbal N, Bhatti IA, Ahmad N, and Zahid M. Response surface methodology application in optimization of cadmium adsorption by shoe waste: A good option of waste mitigation by waste. Ecological Engineering. 2016; 88: $265-275$.

[34] Langmuir I. The constitution and fundamental properties of solids and liquids. Journal of American Chemical Society. 1916; 38: 2221-2295.

[35] Agrawal P, Bajpai AK. Biosorption of chromium(VI) ions from aqueous solutions by iron oxide-impregnated alginate nanocomposites: batch and column studies. Toxicological and Environmental Chemistry. 2011; 93: 12771297.

[36] Freundlich HMF. Over the adsorption in solution. Journal of Physical Chemistry. 1906; 57: 385-471.

[37] Tempkin MI, Pyzhev V. Kinetics of ammonia synthesis on promoted iron catalyst. Acta Physicochimica. URSS. 1940; 12: 327-356.

[38] Dubinin MM, Radushkevich LV. The equation of the characteristic curve of the activated charcoal. Proceedings of the Academy of Sciences, Physical Chemistry Section. 1947; 55: 331-337.

[39] Dada AO, Olalekan AP, Olatunya AM and Dada O. Langmuir, Freundlich, Temkin and Dubinin-Radushkevich isotherms studies of equilibrium sorption of $\mathrm{Zn}^{2+}$ unto phosphoric acid modified rice husk. Journal of Applied Chemistry. 2012; 3: 38-45.

[40] Wang P, Yan T, Wang L. Removal of congo red from aqueous solution using magnetic chitosan composite microparticles. BioResources. 2013; 8: 6026-6043.

[41] Ghaedi M, Hassanzadeh A, Nasiri KS. Multiwalled carbon nanotubes as adsorbents for the kinetic and equilibrium study of the removal of alizarin red S and morin. Journal of Chemical \& Engineering Data. 2011; 56: 2511-2520.

[42] Langergren S, Svenska K. About the theory of so-called adsorption of soluble substances. Kungliga Svenska Vetenskapsakademiens handlingar. 1898; 24: 1-39.

[43] Ho YS, McKay G. Pseudo-second order model for sorption processes. Process Biochemistry. 1999; 34: $451-465$.

[44] Cheung WH, Szeto YS, McKay G. Intraparticle diffusion processes during acid dye adsorption onto chitosan. Bioresource Technology. 2007; 98: 2897-2904.

[45] Chiou MS, Li HY. Adsorption behavior of reactive dye in aqueous solution on chemical cross-linked chitosan beads. Chemosphere. 2003; 50: 1095-1105.

[46] Machado FM, Bergmann CP, Lima EC, Royer B, Dos Santos BD, Fagan SB, at al. Adsorption of reactive blue 4 dye from water solutions by carbon: experiment and theory. Physical Chemistry Chemical Physics. 2012; 14 : 11139-11153. 